Article

\title{
An Algorithm for the Retrieval of High Temporal-Spatial Resolution Shortwave Albedo from Landsat-8 Surface Reflectance and MODIS BRDF
}

\author{
Gang Yang ${ }^{1}\left(\mathbb{D}\right.$, Jiyan Wang ${ }^{1, *}$, Junnan Xiong ${ }^{1,2}$, Zhiwei Yong ${ }^{3}$, Chongchong Ye ${ }^{1}$, Huaizhang Sun ${ }^{4}$, Jun Liu ${ }^{1}$, \\ Yu Duan ${ }^{1}$, Yufeng $\mathrm{He}^{1}$ and Wen $\mathrm{He}^{1}$
}

1 School of Civil Engineering and Geomatics, Southwest Petroleum University, Chengdu 610500, China; 201922000664@stu.swpu.edu.cn (G.Y.); xiongjn@swpu.edu.cn (J.X.); 202131051020@mail.bnu.edu.cn (C.Y.); 201922000655@stu.swpu.edu.cn (J.L.); 201922000658@stu.swpu.edu.cn (Y.D.); 201922000656@stu.swpu.edu.cn (Y.H.); 201922000663@stu.swpu.edu.cn (W.H.)

2 Chinese Academy of Sciences, State Key Laboratory of Resources and Environmental Information System, Institute of Geographic Sciences and Natural Resources Researwangjiyanch, CAS, Beijing 100101, China

3 School of Geoscience and Technology, Southwest Petroleum University, Chengdu 610500, China; 201822000071@stu.swpu.edu.cn

4 School of Geography and Planning, Sun Yat-sen University, Guangzhou 510275, China; sunhzh5@mail2.sysu.edu.cn

* Correspondence: wangjiyan@swpu.edu.cn; Tel.: +86-159-2809-7923

check for updates

Citation: Yang, G.; Wang, J.; Xiong, J.; Yong, Z.; Ye, C.; Sun, H.; Liu, J.; Duan, Y.; He, Y.; He, W. An Algorithm for the Retrieval of High TemporalSpatial Resolution Shortwave Albedo from Landsat-8 Surface Reflectance and MODIS BRDF. Remote Sens. 2021, 13, 4150. https://doi.org/10.3390/ rs13204150

Academic Editor: Belen Franch

Received: 28 September 2021

Accepted: 13 October 2021

Published: 16 October 2021

Publisher's Note: MDPI stays neutral with regard to jurisdictional claims in published maps and institutional affiliations.

Copyright: (c) 2021 by the authors. Licensee MDPI, Basel, Switzerland. This article is an open access article distributed under the terms and conditions of the Creative Commons Attribution (CC BY) license (https:/ / creativecommons.org/licenses/by/ $4.0 /)$.

\begin{abstract}
Variations in surface physicochemical properties and spatial structures can prominently transform surface albedo which conversely influence surface energy balances and global climate, making it crucial to continuously monitor and quantify surface dynamics at fine scales. Here, we made two improvements to propose an algorithm for the simultaneous retrieval of 30-m Landsat albedo, based on the coupling of Landsat- 8 and MODIS BRDF. First, two kinds of prior knowledge were added to disaggregate BRDF, including the Anisotropic Flat Index (AFX) and the Albedo-toNadir reflectance ratio (AN ratio), from MODIS scales into Landsat scales. Second, a simplified data fusion method was used to simulate albedo for the same, subsequent, or antecedent dates. Finally, we validated the reliability and correlations of the algorithm at six sites of the Surface Radiation (SURFRAD) budget network and intercompared the results with another algorithm called the 'concurrent approach'. The results showed that the proposed algorithm had favorable usability and robustness, with a root mean square error (RMSE) of $0.015(8 \%)$ and a mean bias of -0.005 ; while the concurrent approach had a RMSE of 0.026 (14\%) and a mean bias of -0.018 . The results emphasized that the proposed algorithm has captured subtle changes in albedo over a 16-day period.
\end{abstract}

Keywords: surface albedo; high temporal-spatial resolution; Landsat-8; MODIS; BRDF

\section{Introduction}

Surface albedo is the ratio of the reflected light to the total incident energy of a surface in the hemispherical space [1]. It plays an essential role in global climate change, which affects the Earth's energy budget [2-4]. Variations in the physicochemical properties and spatial structure of local objects in turn transform surface albedo [5-8]. At present, surface albedo has been widely used in modelling for radiation and energy balances, numerical weather prediction, atmospheric circulation, and land surface processes [9-13]. Studies have shown that uncertainties in albedo can cause the results of climate and phenology simulations to deviate greatly from real-world conditions [5,14-16]. To minimize any adverse effects on calculations, surface albedo products are usually required to meet the standards for climate modelling, with an uncertainty of less than 5\% [17]. Therefore, there is an urgent need to derive a method for obtaining high-accuracy surface albedo measurements, for monitoring global climate and vegetation phenology. 
Currently, surface albedo can be generated using the Bidirectional Reflectance Distribution Function (BRDF) with a kernel-driven model [18-21]. The short-period and multi-angle reflectance data required can be obtained from the MODerate Resolution Imaging Spectroradiometer (MODIS) [20], Polarization and Directionality of the Earth Reflectance (POLDER) [22], Visible Infrared Imaging Radiometer Suite (VIIRS) [23], Airborne Visible-InfraRed Imaging Spectrometer (AVIRIS) [24], VEGETATION (VGT) [25], PROBA-VEGETATION (PROBA-V) [25,26], or Spinning Enhanced Visible and Infrared Imagers (SEVIRI) [27]. However, these albedo products are too coarse to describe the detailed features of the surface, which hinders downstream calculations of surface processes such as land transformations [28], forest structure [29], fire extent and burn severity [30], and snow cover extent and melt [30-32]. With regard to the cloudless, near-nadir images captured by high-resolution sensors, which provide single-angle reflectivity information to finely reveal surface heterogeneity and vegetation coverage. However, previous studies have demonstrated that ignoring the surface BRDF effects to estimate albedo by single-angle reflectance data can cause relative errors of upper to $45 \%$ [33,34]. Unfortunately, it is difficult and expensive to obtain multi-angle reflectivity information from high spatial-temporal resolution, because currently sensors (such as Landsat satellite series) cannot meet the requirements of high spatial resolution and short revisit periods $[35,36]$. Consequently, this poses a challenging restriction on the generation of high temporal-spatial resolution albedo.

To correct the BRDF effects, several methodologies have been designed to derive high temporal-spatial resolution surface albedo [37-41]. Shuai et al. [37] proposed a methodology (hereafter, the 'concurrent approach') that couples the Landsat-5 surface reflectance and MODIS BRDF product to successfully generate a continuous 30-m albedo product. This method has shown acceptable results for different land uses and land cover ranges of the Surface Radiation (SURFRAD) budget network, with an overall RMSE of less than 0.03 units. Moreover, this method has brought comprehensive and critical benefits to applications in vegetation dynamic monitoring [30,42] and ecosystem assessment [29,43,44]. Although the results of the concurrent approach have met the \pm 0.05 range requirement of climate modeling [15], there are negative deviations (lower retrieved albedo than in situ) in the results for spatially heterogeneous areas. Other recent studies have also shown that the concurrent approach results in a certain negative bias when applied to heterogeneous landscapes $[39,42,45,46]$. The possible sources of this could be excessive atmospheric corrections, the relative spectral response (RSR) of the sensors, or the application of same type anisotropic information to heterogeneous surfaces at the Landsat scale. Shuai et al. [37] pointed out that the albedo to near-nadir reflectance ratio (at view angles $\pm 7.5^{\prime}$ from nadir, hereafter 'AN ratio') of pixels with similar spectral characteristics has a wide distribution, and some land surfaces may have strong spectral similarities but different BRDFs [46]; thus, it would not be reasonable to classify the heterogeneous structure into any single category at the Landsat scale $[39,45]$.

Previous studies have shown that priori classifications of BRDF shapes can significantly improve the accuracy of albedo retrieval [47,48]. Jiao et al. [49] and Zhang et al. [50] have shown that albedo retrieval can achieve high accuracy through the use of a priori Anisotropic Flat Index (AFX) and BRDF archetypes. Therefore, using some ground properties as prior knowledge to classify the BRDF shapes of MODIS pixels could be an effective solution. In addition, surface reflectance varies both slowly and rapidly as a function of time and space affecting the retrieval of albedo, but Landsat- 8 can only provide reflectance data for a 16-day period which makes it difficult to capture any perturbations in surface albedo over a short time. To address this limitation, several studies have proposed multi-temporal algorithms to fuse coarser and finer resolution data for the derivation high temporal-spatial resolution surface reflectance [51-55]. Wang et al. [42] adopted the Spatial and Temporal Adaptive Reflectance Fusion Model (STARFM) [51] to generate high spatial-temporal resolution reflectance, which enhanced the continuity of albedo retrieval by concurrent approach. However, the STARFM does not considered the directional dependence of reflectance as a function (BRDF) of angular anisotropy, which 
would introduce the errors caused by the BRDF effects [55,56]. Considering the directional dependence of reflectance, Roy et al. [56] presented a semi-physical fusion approach to simulate Landsat surface reflectance based on MODIS BRDF data. This approach does not require any adjustment parameters and cannot be affected by missing or contaminated adjacent MODIS pixels. This makes it possible to solve retrieval errors caused by sudden or gradual changes in the ground surface over a short time.

In this study, we further developed the satellite retrieval methodology to reestablish an albedo dataset with high spatial-temporal resolution, by combining Landsat-8 data and Collection V006 MODIS BRDF/albedo products (MCD43). Hence, the main aims were to: (1) reduce uncertainties in applications involving heterogeneous landscapes and improve the estimation accuracy of retrievals by taking advantage of existing anisotropic information to effectively extract prior BRDF knowledge, and (2) capture short-term regional disturbances in albedo, based on a simplified data fusion algorithm. The usability and operability of these processes will provide a reference for the generation of high spatial-temporal resolution albedo datasets using the data from other satellite systems.

\section{Materials and Methods}

\subsection{Study Areas and Field Data}

Crucial in the generation of fine-resolution albedo retrieval products is a requirement for the field validation on different surface types and seasonal characteristics over longterm temporal series. Surface albedo measured in situ using tower-mounted pyranometers has been widely used to verify the surface albedo obtained from satellite data [30,46,57-60]. Since 1995, the SURFRAD budget network (https:/ / gml.noaa.gov/grad/surfrad/index. html) has been committed to supporting climate research through accurate, continuous, and long-term field measurements. In addition, sites with extended areas of homogeneous geomorphology and vegetation have been selected; field equipment have been established for taking measurements at these sites-thus, fixed-point measurements can be qualitatively used to represent large areas. These sites are called spatial representative sites and are more suitable for the verification of albedo in pixels with larger spatial scales (such as MODIS pixels). However, for non-representative sites with large spatial variability, the field measurement data are not sufficient for representing the albedo of extended areas [61]. At measurement sites, the tower-height, effective field-of-view of the downward-facing pyranometer, and area of ground covered are approximately $10 \mathrm{~m}, 1.8 \pi \mathrm{sr}$, and $126 \mathrm{~m}$ in diameter, respectively [46]. Coverage areas are larger than the spatial resolution of Landsat, which aids the verification of the accuracy of the 30-m albedo retrieval results at measurement sites $[61,62]$. In this study, we evaluated the accuracy of the retrieval results using ground measurements from six SURFRAD sites (Table 1). And Figure 1 depicts the land coverage types and locations of the six stations.

Table 1. SURFRAD ground stations used.

\begin{tabular}{ccccc}
\hline Site Name $^{\mathbf{1}}$ & Site ID & Latitude Longitude & Land Cover Type & Landsat Path/Row $^{\text {Scenes }}{ }^{2}$ \\
\hline Table Mountain & TBL & $40.1256^{\prime} \mathrm{N}, 105.2378^{\prime} \mathrm{W}$ & Grassland & $34 / 32,33 / 32$ \\
Desert Rock & DRA & $36.6232^{\prime} \mathrm{N}, 116.0196^{\prime} \mathrm{W}$ & Sparse vegetation, desert & $40 / 34,40 / 35$ \\
Fort Peck & FPK & $48.3080^{\prime} \mathrm{N}, 105.1018^{\prime} \mathrm{W}$ & Grassland & $35 / 26,36 / 26$ \\
Goodwin & GWN & $34.2547^{\prime} \mathrm{N}, 89.8729^{\prime} \mathrm{W}$ & Grassland, deciduous trees & $23 / 36,22 / 36$ \\
Penn State & PSU & $40.7203^{\prime} \mathrm{N}, 77.9310^{\prime} \mathrm{W}$ & Agriculture & 15 \\
Bondville & BON & $40.0516^{\prime} \mathrm{N}, 88.3733^{\prime} \mathrm{W}$ & Agriculture & $15 / 32$ \\
\hline
\end{tabular}

${ }^{1}$ The sites in italics are spatially representative, with extended areas of homogeneous surfaces. ${ }^{2}$ The number of selected scenarios, filtered to exclude scenarios with cloud cover greater than $30 \%$ and with visible cloud cover at the sites. 

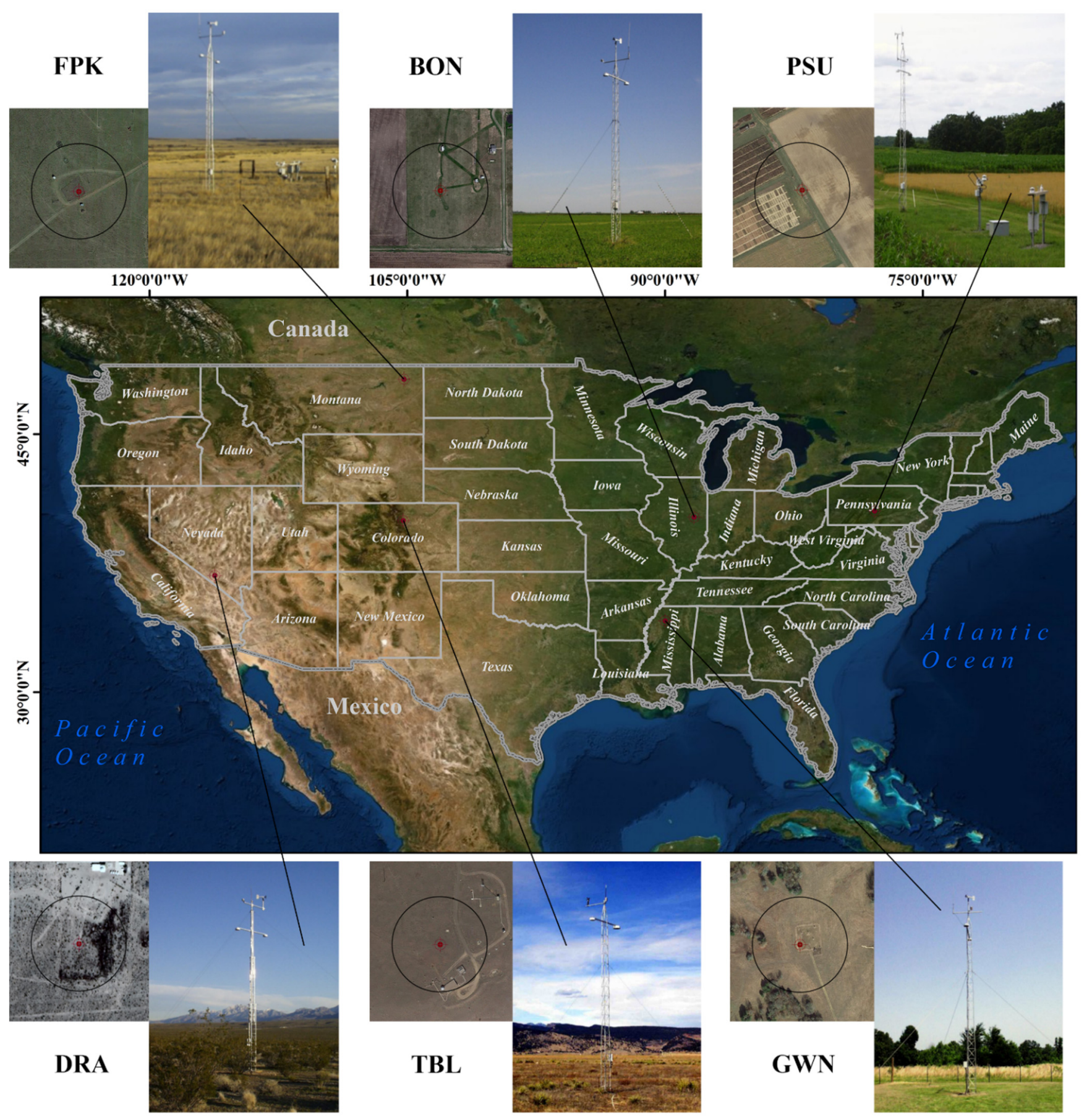

Figure 1. Images of the six ground sites and towers (Table 1) used in this study were acquired from high-resolution satellite data on https://www.google.com/earth. The red markers and black circles represent the location of the measurement towers and the 126-m diameter area they covered, respectively.

The albedo value measured in situ at Landsat local time is the average of the fieldmeasured values of the first half hour and the next half hour of Landsat's transit time. As instantaneous conditions such as clouds or birds cause instantaneous disruptions to the accuracy of pyranometer measurements, noise is included in the analysis of albedo records. Therefore, the measured albedo and the ratio of diffuse light to sky light per minute with unusually large standard deviations are excluded [46]. Additionally, while all in situ field measurements with clear days and no clouds were included, field measurements with cloud cover greater than $30 \%$ and diffuse-to-total irradiance ratios greater than $30 \%$ at local solar noon (LSN) were excluded. The measurement towers cover the same area as a 
$3 \times 3$ Landsat grid. For comparisons of the Landsat albedo to the measured in situ values, we also used the cosine-factor-based upscaling method to aggregate the Landsat albedos from $30-\mathrm{m}$ resolutions to the measurement tower area of coverage $[37,63]$.

\subsection{Satellite Data}

In this study, we used the latest version of the daily concurrent MODIS MCD43 V006 product and Landsat- 8 OLI surface reflectance product to retrieve albedo for the period between 2013 and 2016. The Landsat- 8 data were obtained from the United States Geological Survey (USGS) Earth Resources Observation and Science (EROS) Center Science Processing Architecture (ESPA) (https: / / espa.cr.usgs.gov), including 85 cloudless scenes over nine different paths/rows (Table 1). The accuracy of Landsat- 8 OLI surface reflectance depends on atmospheric correction; thus, we used the Land Surface Reflectance Code (LaSRC), which is an accurate atmospheric correction algorithm specially designed by USGS for Landsat-8 data [64], for atmospheric correction. The concurrent MODIS BRDF/albedo data (Collection 6) were downloaded from the Land Processes Distributed Active Archive Center of the US National Aeronautics and Space Administration (NASA) and USGS partnership (https:/ / lpdaac.usgs.gov). The MCD43 BRDF V006 product, which has been validated in the third stage [65], uses high-quality cloudless MODIS surface reflectance data within 16-days to retrieve surface anisotropy information through a kernel-driven model [20,61,66-68]. It includes surface BRDF parameters (MCD43A1), BRDF parameter inversion quality (MCD43A2), albedo (MCD43A3), and Nadir BRDF-Adjusted Reflectance (NBAR) (MCD43A4), and encourages users to use frequency-band-specific quality control (QA) to obtain the highest quality complete inversion results $[45,61,69]$. Therefore, the high quality BRDFs marked 0 were used. Both MCD43 BRDF and Landsat-8 OLI data are available from https: / / earthdata.nasa.gov.

\subsection{Methods}

\subsubsection{Theoretical Basis to Retrieve Albedo}

The albedo inherent to natural surfaces depend on the anisotropic properties of the land itself, the BRDF, which describes how surface reflectivity changes with the Solar Zenith Angle (SZA) and viewing angle [70]. Currently, the recognized kernel-driven model consists of an empirical, linear combination of three scattering properties, that can accurately characterize the BRDF of surface patches [18,71,72]:

$$
R_{\lambda}\left(\theta_{v}, \theta_{s}, \varphi\right)=f_{i s o, \lambda}+f_{v o l, \lambda} K_{v o l}\left(\theta_{v}, \theta_{s}, \varphi\right)+f_{\text {geo }, \lambda} K_{g e o}\left(\theta_{v}, \theta_{s}, \varphi\right)
$$

Among them, $R$ is the Bidirectional Reflectance Factor (BRF); $\lambda$ is the given MODIS spectral band; $\theta_{v}$ is the observation zenith angle; $\theta_{s}$ is the SZA; $\varphi$ is the relative azimuth; $\theta_{v}$ and $\varphi$ are set to 0 to simplify the calculation when calculating the BRF for Landsat viewing. $F_{i s o}, f_{\text {vol }}$ and $f_{\text {geo }}$ are the three spectral constants of BRDF, representing isotropic scattering, volume scattering and geometric optical scattering, respectively. $K_{\text {vol }}$ is the volume scattering kernel called Ross-Thick [71,72]. $K_{\text {geo }}$ is the geometric optical scattering kernel called Li-Sparse-Reciprocal $[18,73]$. Once the surface anisotropy is clearly represented by the BRDF parameters, the Black-Sky Albedo $\left(\mathrm{BSA}, \bar{R}_{\lambda}\right)$ is obtained by integrating the viewing angles over the entire hemisphere at any given SZA. The diffuse light is further integrated at all illumination angles to obtain the White-Sky Albedo (WSA, $\left.\overline{\bar{R}}_{\lambda}\right)$.

$$
\begin{aligned}
& \bar{R}_{\lambda}\left(\theta_{s}\right)=\mathrm{f}_{i s o, \lambda}+f_{\text {vol, } \lambda}\left(H_{\text {vol_ } 0}+H_{\text {vol__ }} \theta_{s}{ }^{2}+H_{\text {vol_ } 2} \theta_{s}{ }^{3}\right)+f_{\text {geo }, \lambda}\left(H_{\text {geo } \_0}+H_{\text {geo_ } 1} \theta_{s}{ }^{2}+H_{\text {geo_ } 2} \theta_{s}{ }^{3}\right) \\
& \overline{\bar{R}}_{\lambda}=\mathrm{f}_{i s o, \lambda}+f_{v o l, \lambda} H_{v o l}+f_{g e o, \lambda} H_{g e o}
\end{aligned}
$$

where $H$ is the integral value of the kernel function, please refer to Lucht et al. [18] for specifics. At the same time, if the ratio of diffuse light radiation to the total radiation is given under certain light conditions $\left(S_{\theta_{s}}\right)$, combined with the BSA and WSA, the actual (or blue-sky) albedo $\left(\overline{\bar{R}}_{\lambda}\left(\theta_{S}\right)\right)$ for a certain time such as could be obtained at the surface area by satellites for that SZA $[18,74,75]$. 


$$
\overline{\bar{R}}_{\lambda}\left(\theta_{s}\right)=\left(1-S_{\theta_{s}}\right) \cdot \bar{R}_{\lambda}\left(\theta_{s}\right)+S_{\theta_{s}} \cdot \overline{\bar{R}}_{\lambda}
$$

At present, it is hard to directly retrieve finer-resolution albedo with the kernel-driven model, due to the difficulty in obtaining finer-resolution BRDFs. Fortunately, the concurrent approach proposed by Shuai et al. [37] provides an idea for obtaining finer-resolution BRDF. The concurrent approach made two assumptions that the land surface remains invariable over a 16-day period and the AN ratio are similar in the homogeneous regions covered by both MODIS and Landsat pixels (Equation (5)). Then, after unsupervised classification, it finds the representative pixels (i.e., pure pixel) under the spatial resolution of MODIS, and calculates the black-sky and white-sky AN ratio, $\bar{a}_{\lambda}$ and $\overline{\bar{a}}_{\lambda}$ (Equation (6)).

$$
\begin{array}{rlrl}
\bar{a}_{\lambda, l}\left(\Omega_{l}\right) & \approx \bar{a}_{\lambda, m}\left(\Omega_{l}\right), & \overline{\bar{a}}_{\lambda, l}\left(\Omega_{l}\right) \approx \overline{\bar{a}}_{\lambda, m}\left(\Omega_{l}\right) \\
\bar{a}_{\lambda, l}\left(\Omega_{l}\right)=\frac{\bar{R}_{\lambda, m}\left(\theta_{s}\right)}{R_{\lambda, m}\left(\Omega_{l}\right)}, & \overline{\bar{a}}_{\lambda, l}\left(\Omega_{l}\right)=\frac{\overline{\bar{R}}_{\lambda, m}}{R_{\lambda, m}\left(\Omega_{l}\right)}
\end{array}
$$

where $m$ denotes the spatial resolution of MODIS $500-\mathrm{m}$, and $l$ represents the spatial resolution of Landsat $30-\mathrm{m} . \Omega_{1}$ is the geometry for the Landsat radiance observation. Then, assuming the land surface remains invariable over a 16-day period, the spectral AN ratio of these pure pixels are used to calculate the spectral albedo for Landsat resolution through Equations (7) and (8), according to the frequency band correspondence between Landsat and MODIS sensors (as shown in Table 2).

$$
\begin{gathered}
\bar{R}_{\lambda, l}\left(\theta_{s}\right)=\bar{a}_{\lambda, l}\left(\Omega_{l}\right) \cdot R_{\lambda, l}\left(\Omega_{l}\right)=\bar{a}_{\lambda, m}\left(\Omega_{l}\right) \cdot R_{\lambda, l}\left(\Omega_{l}\right) \\
\overline{\bar{R}}_{\lambda, l}=\overline{\bar{a}}_{\lambda, l}\left(\Omega_{l}\right) \cdot R_{\lambda, l}\left(\Omega_{l}\right)=\overline{\bar{a}}_{\lambda, m}\left(\Omega_{l}\right) \cdot R_{\lambda, l}\left(\Omega_{l}\right)
\end{gathered}
$$

Table 2. Equivalence of MODIS and Landsat-8 OLI spectral bands.

\begin{tabular}{cl}
\hline MODIS & \multicolumn{1}{c}{ Landsat-8 OLI } \\
\hline Band 1 $(0.620-0.670 \mu \mathrm{m})$ & Band 4 $(0.636-0.673 \mu \mathrm{m})$ \\
Band 2 $(0.841-0.876 \mu \mathrm{m})$ & Band 5 $(0.851-0.879 \mu \mathrm{m})$ \\
Band 3 $(0.459-0.479 \mu \mathrm{m})$ & Band 2 $(0.452-0.512 \mu \mathrm{m})$ \\
Band 4 $(0.545-0.565 \mu \mathrm{m})$ & Band 3 $(0.533-0.590 \mu \mathrm{m})$ \\
Band 6 $(1.628-1.652 \mu \mathrm{m})$ & Band 6 $(1.566-1.651 \mu \mathrm{m})$ \\
Band 7 $(2.105-2.155 \mu \mathrm{m})$ & Band 7 $(2.107-2.294 \mu \mathrm{m})$ \\
\hline
\end{tabular}

\subsubsection{BRDF Inversion by Prior AN Ratio and AFX}

Although previous studies of surface anisotropy [33,76,77] have discovered an association between characteristic BRDF shapes and various homogeneous surfaces, it is unavoidable that the BRDF shapes retrieved from satellite data are frequently inexact because veracity is muted by heterogeneous surfaces and complicated vegetation types and fragmented structures within the same pixel [37]. The lack of classification of pure pixels in the entire Landsat scene has further hampered the acquisition of exact BRDF shapes $[39,45,46]$. To address this limitation, we propose to assume that, the near-infrared (NIR) band prior knowledge can represent 500-m information, which is roughly the same as 30-m information within.

In the search for suitable prior knowledge that satisfies this hypothesis, the anisotropic information and ground scattering properties were considered. The spectral AN ratio, which is related to anisotropic information and the SZA, has demonstrated the capacity to capture BRDFs under specific solar illumination conditions. In particular, it is the key factor for computing spectral albedo. In this study, the AN ratio was used as prior knowledge for the determination of BRDF. Figure 2A,B shows the spectral AN ratio of the Landsat red band and NIR band, using the spectral conversion coefficients provided by He et al. [78]. The histograms of AN ratios in the red band and NIR band were obtained through unsupervised classification (Figure 2C,D). It is worth noting that the AN ratio shown in Figure 2A,B is slightly different from the AN ratio under real-world conditions, because the $500-\mathrm{m}$ grids smoothed the $30-\mathrm{m}$ signal. The red band AN ratio is spatially 
fragmented (Figure 2A), while the NIR band AN ratio is relatively smoother within $500 \mathrm{~m}$ (Figure 2B). At the same time, the NIR band AN ratio of each type (Figure 2D) is more concentrated than that of the red band (Figure 2C), which indicates that the NIR AN ratio is more suitable to satisfy the hypothesis. Therefore, the NIR band AN ratio was used as one of the links that connect different scales.

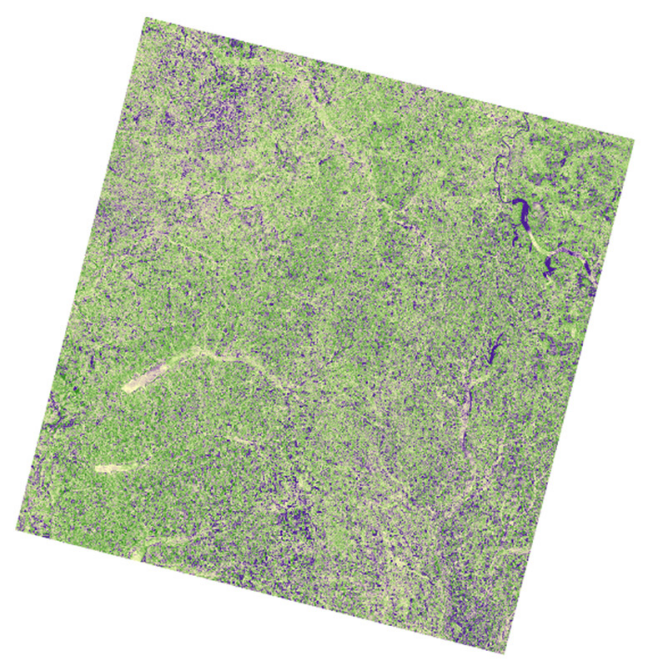

(A) Red band
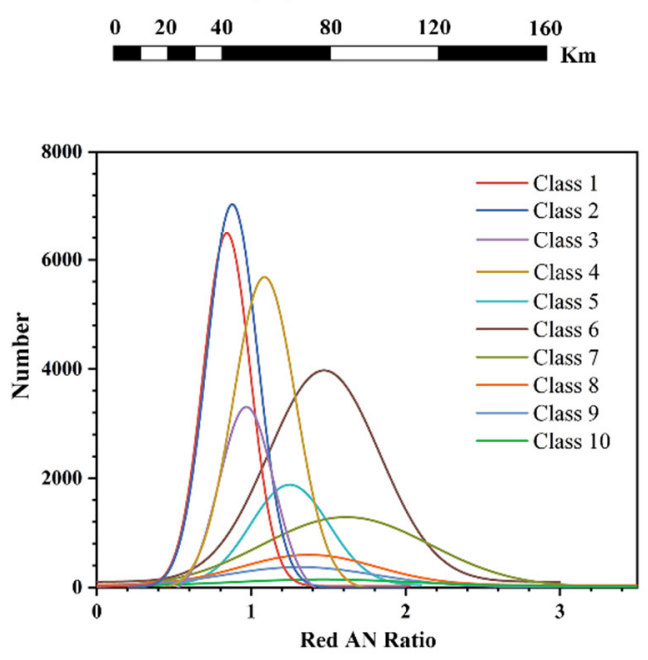

(C)

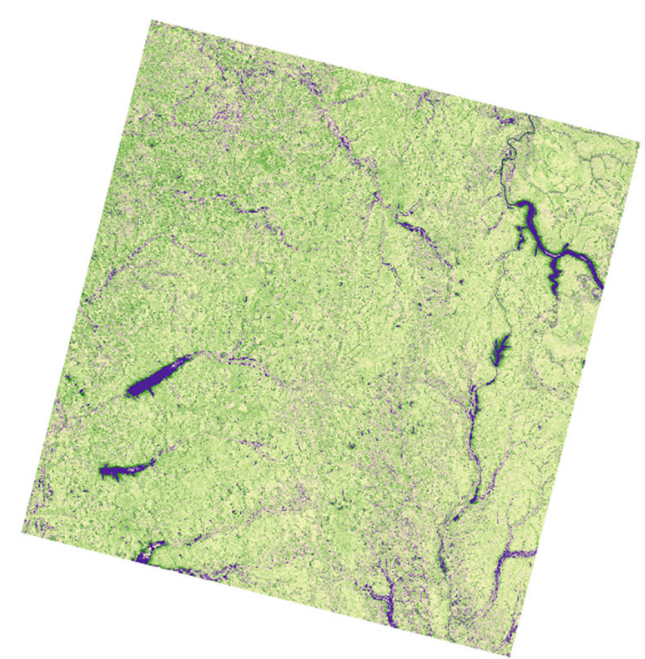

(B) NIR band
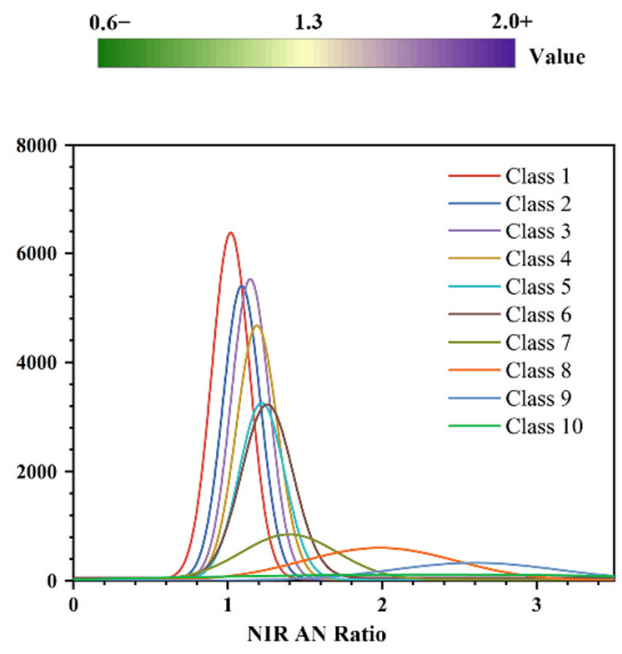

(D)

Figure 2. Spatial distribution of the ratio of MODIS WSA (white-sky albedo, after converting spectral coefficients) to Landsat nadir reflectance, and histograms of AN ratio (Albedo-to-Nadir reflectance ratio), obtained by unsupervised classification, in Northwest Mississippi, on 9 April 2014. (A): red band AN ratio; (B): near-infrared band AN ratio; (C): histograms of red band AN ratio; (D): histograms of near-infrared band AN ratio.

The BRDF shapes of the ground features depend not only on the spectral AN ratio but also on the scattering characteristics. Therefore, it is necessary to introduce further a priori knowledge to simultaneously describe the scattering properties of ground objects. The anisotropic flat index (AFX) is a vegetation index that represents a nonlinear response to changes in surface structure [79]. Further classification of AFX can produce BRDF archetypes, which can be effectively used to classify BRDFs based on ground scattering properties [50,79-81]. A study by Jiao et al. [49] showed that the range of variation of AFX in the NIR band is lower than that in the red band, indicating that the NIR band AFX is more stable than the red band AFX. Therefore, the NIR AFX was also used to retrieve the BRDFs of pure pixels, as follows: 


$$
A F X_{N I R}=1+\frac{f_{v o l, N I R}}{f_{i s o, N I R}} \times H_{v o l}+\frac{f_{g e o, N I R}}{f_{i s o, N I R}} \times H_{g e o}
$$

The NIR AFX depends on two parameters: geometric optics and volume scattering. When the volume scattering effect is greater than the geometric optical effect, AFX $>1$; when the geometric optical effect is larger than the volume scattering effect, $\mathrm{AFX}<1$; when the two effects are very close, $\mathrm{AFX} \approx 1$. AFX reveals the relationship between the surface scattering properties and the BRDF archetypes [49,79].

In summary, we used the NIR AFX and NIR AN ratio as prior knowledge for BRDF inversion, fully utilizing all the high-quality BRDF data. Additionally, the BRDF spatial distribution of each type was more suitable for obtaining the scattering properties and angular characteristics of each location without the use of other auxiliary data. Refer to Section 3.2. for specific operations.

\subsubsection{Narrowband-to-Broadband Conversion}

The spectral albedo cannot satisfy the research of energy balance on the land surface, it is necessary to further convert the narrowband spectral albedo into broadband shortwave (SW) albedo [57]. Narrowband-to-broadband (NTB) conversion coefficients can be generated by simulating the spectral responses of various ground objects in the digital spectrum library, based on the sensor's extensive radiative transmission [57,82]. This method has been verified to be sufficient for estimating shortwave albedo from spectral albedo $[30,57,63,82]$. The surface albedo is generated through the conversion coefficients. In this study, we use the conversion coefficients for Landsat-8 OLI developed by Wang et al. [30] under the condition of no snow.

\subsubsection{Landsat Albedo Modulation}

The assumption that the surface reflectance remains unchanged within 16-day periods is reasonable when the surface changes slowly during the dormant season [37]. However, during the growing season or the period of large-scale changes in land cover (such as fire, snow cover, and melt), this assumption is broken because land cover types change rapidly. Hence, we adopted a multi-temporal fusion method of MODIS-Landsat data based on the MODIS backup algorithm [52], assuming that the MODIS modulation term $C$ represents the change in reflectance of the Landsat wavelength with similar spectra at the Landsat scale. The prediction of Landsat reflectance at $t_{2}$ from the Landsat observation data at $t_{1}$ is defined as:

$$
C=\frac{R_{\lambda, m, t_{2}}\left(\Omega_{l 2}\right)}{R_{\lambda, m, t_{1}}\left(\Omega_{l 1}\right)} \approx \frac{R_{\lambda, l, t_{2}}\left(\Omega_{l 2}\right)}{R_{\lambda, l, t_{1}}\left(\Omega_{l 1}\right)}, \quad \quad R_{\lambda, l, t_{2}}\left(\Omega_{l 2}\right)=C \times R_{\lambda, l, t_{1}}\left(\Omega_{l 1}\right)
$$

As the MCD43A1 product provides shortwave BRDF parameters, we simplify the modulation term C. Similarly, we suppose that the MODIS short-wave (SW) albedo change is similar to the short-wave albedo change at the Landsat scale [42]. $C_{S W}$ represents the multiplicative modulation term of the short-wave albedo, which is described as:

$$
C_{S W}=\frac{R_{\lambda_{S W}, t_{2}}\left(\Omega_{l}\right)}{R_{\lambda_{S W}, t_{1}}\left(\Omega_{l}\right)}
$$

Then, we can combine Equations (4), (10), and (11), based on the Landsat surface reflectance data on the $i$-th day and the MODIS data on the $j$-th day ( $j$ ranges from 8 days before $i$ to 8 days after $i$ ); finally, retrieve the actual (blue sky) albedo of Landsat on the $j$-th day:

$$
\overline{\bar{R}}_{\lambda, l, t_{j}}\left(\theta_{s}\right)=C_{S W} \times\left(\left(1-S_{\theta_{s}}\right) \cdot \bar{R}_{\lambda, l, t_{i}}\left(\theta_{s}\right)+S_{\theta_{s}} \cdot \overline{\bar{R}}_{\lambda, l, t_{i}}\right)
$$

Thus, the calculation procedure can be simplified, based on the existing data, avoiding any impact arising from the disparity between the spectral response functions for the two sensors [42,78]. 


\subsection{Data Processing}

\subsubsection{Data Preparation}

The data processing in this article is shown in the flowchart (Figure 3). In order to combine MODIS BRDF and Landsat surface reflectance, we need to establish the connection between them. First, a cluster-based unsupervised classification (Iterative Self-Organizing [ISO] data analysis) is used to classify the Landsat- 8 data after atmospheric correction (the number of categories is set to 10-15). Then, Landsat- 8 coordinate system is converted from the default WGS-84 projection to the SIN projection to associate with MODIS anisotropy information. Next, the percentage of each type of $30-\mathrm{m}$ patch throughout the MODIS grid is calculated. The higher this percentage is, the more applicable the BRDF of coarseresolution pixels is to the finer $30-\mathrm{m}$ pixels. All the $500-\mathrm{m}$ pixels, whose category percentage is higher than the given threshold $(60 \%)$, are marked as pure pixels $[40,83]$, that is, the representative pixels. At the same time, the percentage is exported as a quality control dataset. Lastly, the highest-quality MODIS BRDF parameters are extracted from the concurrent MCD43A1 BRDF products (the quality is determined by the MCD43A2 QA marks). For those categories that do not have pixels to meet the threshold conditions, the pixels in the top $15 \%$ of the percentage in those categories are extracted, and the extracted pixels of those categories are marked as low quality (Table 3).

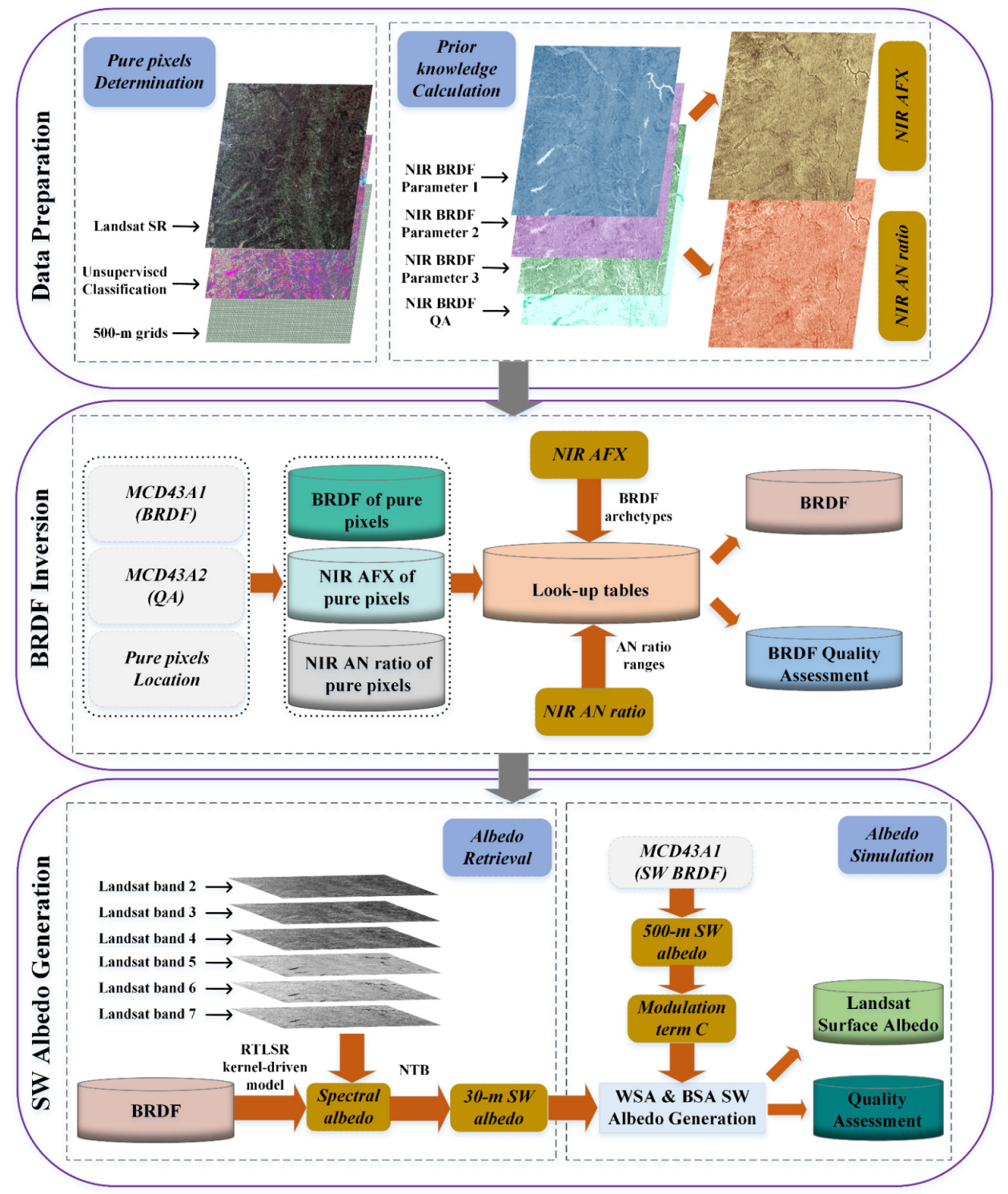

Figure 3. Flowchart for the Landsat/MODIS 30-m albedo retrievals. 
Table 3. The outcomes of BRDF inversion and the corresponding quality labels for each case.

\begin{tabular}{cccccc}
\hline Cases & Representation & AFX & AN Ratio & Quality Labels & Meaning \\
\hline A & Y & Y & Y & 0 & High quality \\
B & Y & Y & Y & 1 & Good quality \\
C & Y & N & N & 2 & Good quality \\
D & N & N/A & N/A & 2 & Low quality \\
E & N / & N/A & N/A & Low quality & NULL \\
F & & & & & 15 \\
\hline
\end{tabular}

${ }^{1}$ Inversion failure.

\subsubsection{BRDF Inversion}

In the regions with similar spectral types of ground objects, BRDF parameters of all high-quality pure pixels can be extracted by the quality control QA (MCD43A2). However, the value of BRDF parameters is still dispersed (Figure 4A). After the band quality control QA in the MCD43A2, we find the high-quality NIR parameters of the BRDF in the MCD43A1 and then calculate the NIR AN ratio (Equation (6)). The WSA after quality control in MCD43A3 and the isotropic BRDF parameters in MCD43A1 are utilized to obtain the white-sky AFX (Equation (9)) of each 500-m patch. To determine BRDF shapes, the consideration is required to get appropriate threshold ranges of the prior AN ratio and AFX. For AFX, we refer to the threshold ranges of six BRDF archetypal parameters by Jiao et al. [49], as shown in Table 4. With regard to the AN ratio, threshold range of each patch is set as $\left[\mathrm{AN}_{\mathrm{NIR}}, \mathrm{MEAN}-0.05, \mathrm{AN}_{\mathrm{NIR}}\right.$ MEAN + 0.05]. $\mathrm{AN}_{\mathrm{NIR}}$, MEAN is the average AN ratio of a $500-\mathrm{m}$ patch in 16 days.

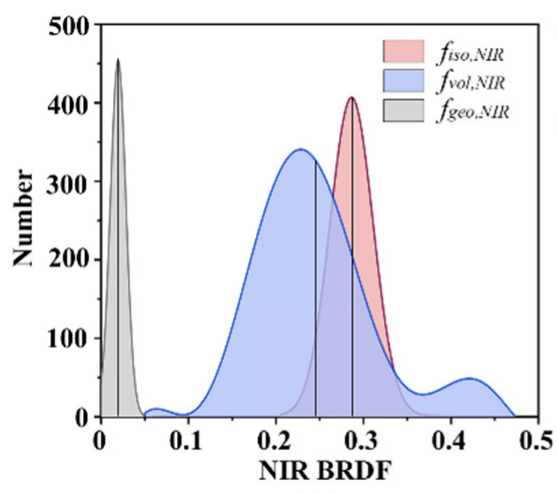

(A)

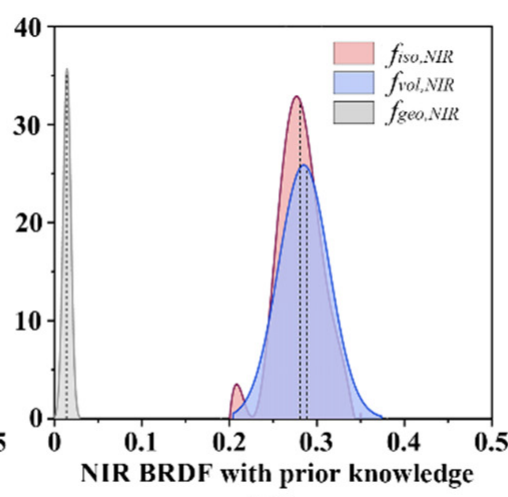

(B)

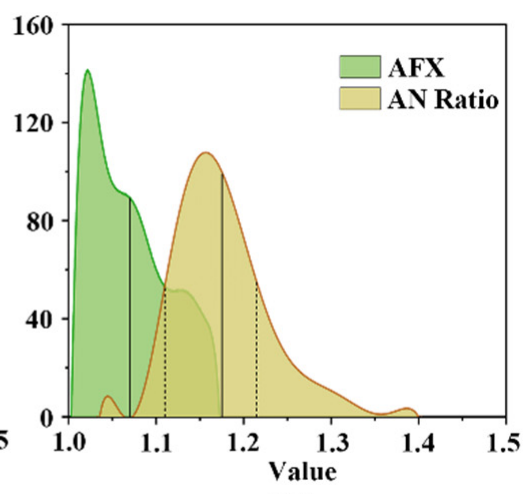

(C)

Figure 4. Histograms of the pure pixels BRDF parameter values of Class 1 in the Landsat scene of Northwestern Mississippi on April 09, 2014. The solid lines represent the value corresponding to the concurrent approach, and the dashed lines represent the value corresponding to the new algorithm. (A): the pure pixel BRDF parameters without prior knowledge; (B): the pure pixel BRDF parameters with prior knowledge; (C): AFX (the Anisotropic Flat Index) and AN ratio (Albedo-toNadir reflectance ratio).

Table 4. AFX (the Anisotropic Flat Index) and six BRDF Archetypal ranges in NIR Band offered by Jiao et al. [49].

\begin{tabular}{ccc}
\hline Band & AFX Range & Mean AFX \\
\hline & {$[0.541,0.804]$} & 0.744 \\
& {$[0.804,0.896]$} & 0.853 \\
NIR & {$[0.896,0.966]$} & 0.931 \\
& {$[0.966,1.042]$} & 1.002 \\
& {$[1.042,1.142]$} & 1.091 \\
\hline
\end{tabular}


To seek the exact properties that each pixel has, we build a look-up table (LUT) for the AN ratio and AFX of each category [63]. Then, each type of pure pixel that satisfies both the $\mathrm{AN}$ ratio and the AFX threshold range is a spatial representative pure pixel. The average value of selected pure pixels is taken as the reliable BRDF parameters, and their values (Figure 4B) are more centralized than before (Figure 4A). The values of AFX and AN ratio obtained by the new algorithm (dashed line) are no longer fixed to those corresponding to the concurrent approach (solid line), but change with different spatial positions (Figure 4C). Note that when the inversion fails, the BRDF average value of the successful inversion within 16 days is used to fill, and the pixels of these categories are marked as low quality. All quality marks are output with the BRDF inversion results, see Table 3 for details.

\subsubsection{Shortwave Albedo Generation}

In the Landsat scene, each 30-m patch has been assigned a daily change BRDF within a 500-m grid. This provides a basis for the estimation of 30-m daily surface reflectance and shortwave albedo under any zenith angle. After obtaining the BRDF parameters of all plots, these BRDF parameters are used to calculate the black-sky and white-sky albedo of each band under the Landsat viewing angle and solar illumination. Then, the spectral AN ratio of all bands is obtained through Equation (6). Landsat data provide the surface reflectance of each 30-m patch, which can be correlated with the spectral AN ratio of each patch to gain the spectral albedo through Equations (7) and (8). Then, shortwave albedo is generated through narrowband-to-broadband conversion, based on extensive radiant transmission simulation. The modulation term $C_{S W}$ can reflect the changes in the albedo of the date that Landsat has not observed. Hence, we use the BRDF parameters of shortwave albedo in MCD43A1 to calculate the actual albedo and gain the multiplication modulation term $C_{S W}$ of daily albedo. Then, $C_{S W}$ is used to transform the albedo that has been retrieved for the day through Equation (12). Finally, the Landsat albedo is generated.

\section{Results}

\subsection{Validation Results at SURFRAD}

The results show the time series comparison of Landsat albedo obtained by the concurrent approach and the new algorithm at six sites (Figure 5A-F). Figure 6 shows the validation results of the concurrent approach product (hereafter ' $C A P^{\prime}$ ') and the new albedo product (hereafter ' $\mathrm{NP}^{\prime}$ ) at each site. In the extended Landsat coverage area, the ground truth was well described by in situ measurements. Landsat albedo retrieval results showed seasonal characteristics, with the highest value during the dormant period and the lowest value when entering a complete growth period.

During growth and dormancy periods, the DRA was uniformly covered by deserts and sparse vegetation, which occupied most regions covered by the Landsat data (Figure 5A). Similarly, around the FPK and TBL sites (Figure 5C,E), there was relatively homogeneous land cover, which enabled the retrieval of albedo from satellite data, and the collection of a large amount of effective and coherent anisotropy information (i.e., pure pixels). At three representative sites, the two Landsat albedo retrievals were in good agreement with the field measurement, with positive and negative deviations evenly distributed. The slopes of representative sites were almost within the 5\% uncertainty range (Figure 6A,C,E). Therefore, both albedo products showed high consistencies with field measurements at the representative sites. However, with regard to the non-representative sites of BON, PSU, and GWN, CAP satellite retrieval results poorly represented seasonal characteristics, translating to large deviations during dormant periods and small deviations during growing periods (Figure 5B,D,F). The uncertainties of non-representative sites were higher than $5 \%$, but the slopes of NP were closer to 1 than the slopes of CAP (Figure 6B,D,F).

Table 5 summarizes the evaluation of the accuracy of the two albedo products relative to in situ measurements at six sites. After excluding cloud-contaminated albedo values, the blue-sky albedo values from NP and CAP against in situ were used for statistics. Uncertainty (root mean square error [RMSE]), accuracy (median deviation), offset (mean 
bias) and linear correlation (slope and correlation coefficient $\left[R^{2}\right]$ ) for satellite retrievals were included in the statistical processing [65]. The RMSE, median deviation, and mean bias of CAP at representative sites were $0.015,-0.014$, and -0.012 , respectively, but showed poor results at non-representative sites, with RMSE of 0.032 , median deviation of -0.032 , and mean bias of -0.030 (Table 5). However, NP showed a slight improvement at the three representative sites, with RMSE, median deviation and mean bias of 0.011, 0.004 and 0.002, respectively. For the three non-representative sites of satellite retrievals, the RMSE dropped from 0.032 to 0.020 , median deviation decreased from -0.032 to -0.019 and the mean bias decreased from -0.030 to -0.015 . Therefore, NP had less uncertainty and better accuracy than CAP.
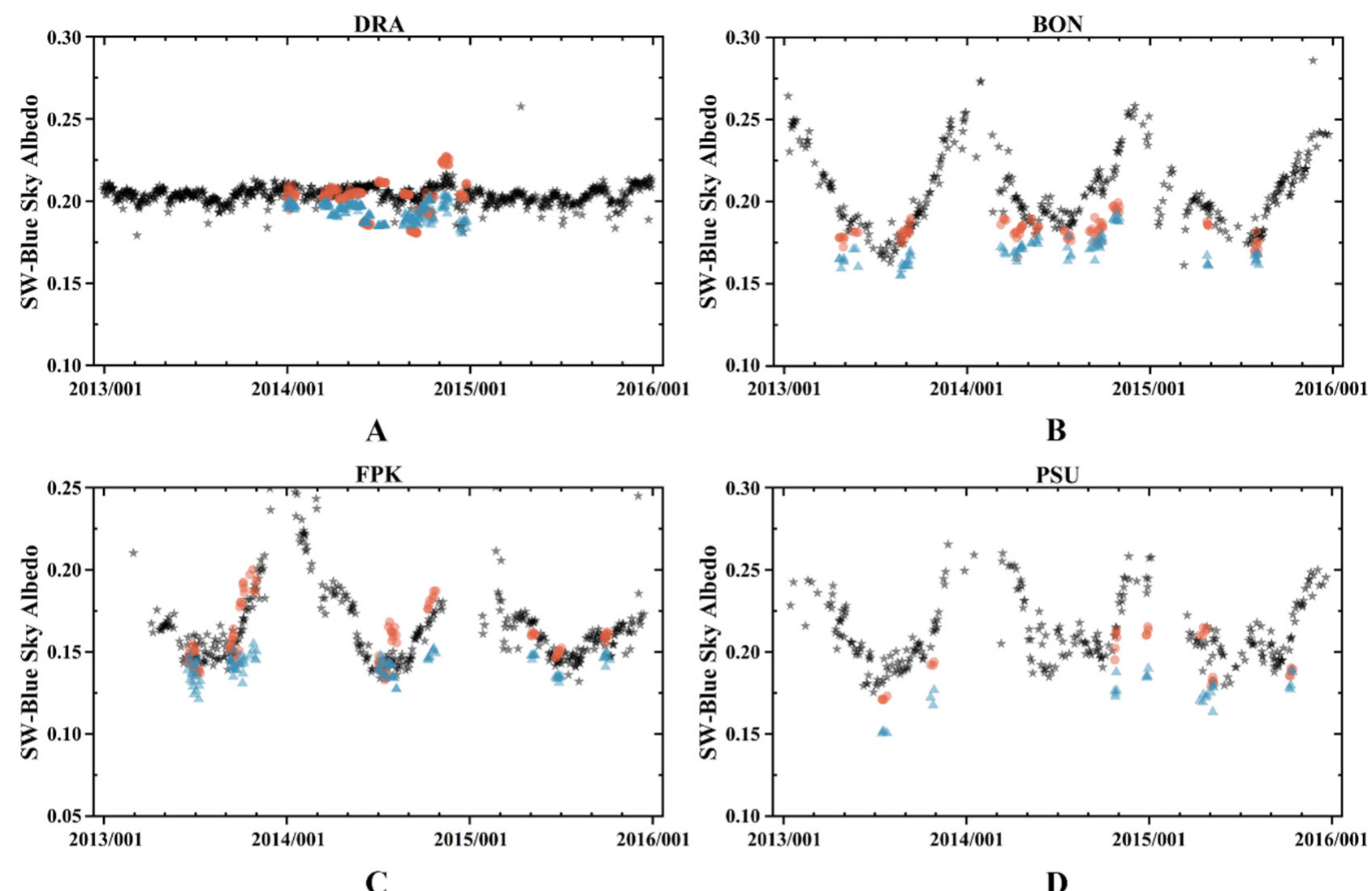

C

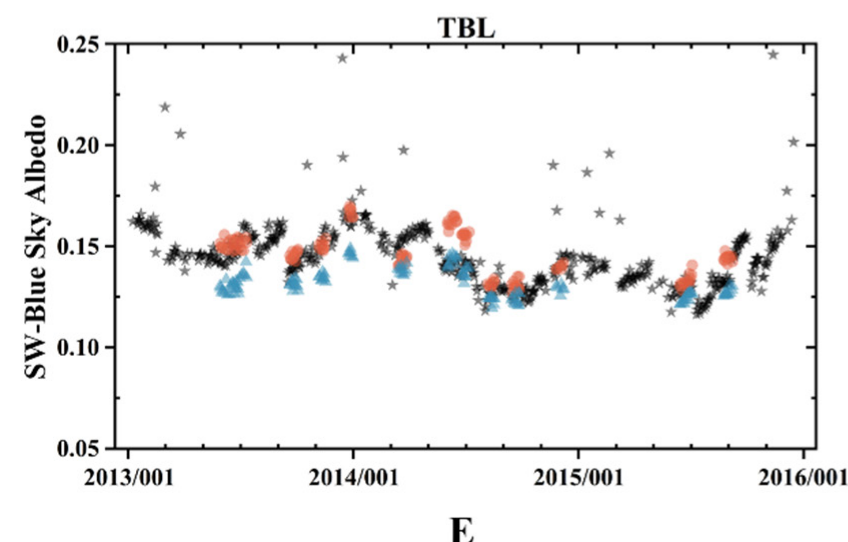

* In situ

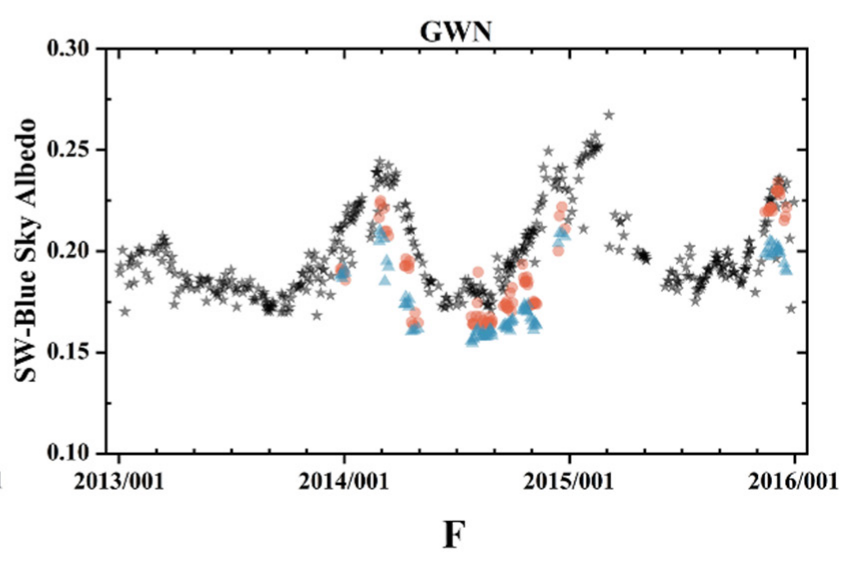

- New algorithm

Figure 5. Time series comparison of in situ albedo of six sites against concurrent approach and new algorithm albedo from 2013 to 2015. (A): Desert Rock (DRA); (B): Bondville (BON); (C): Fort Peck (FPK); (D): Penn State University (PSU); (E): Table Mountain (TBL); (F): Goodwin Creek (GWN). 

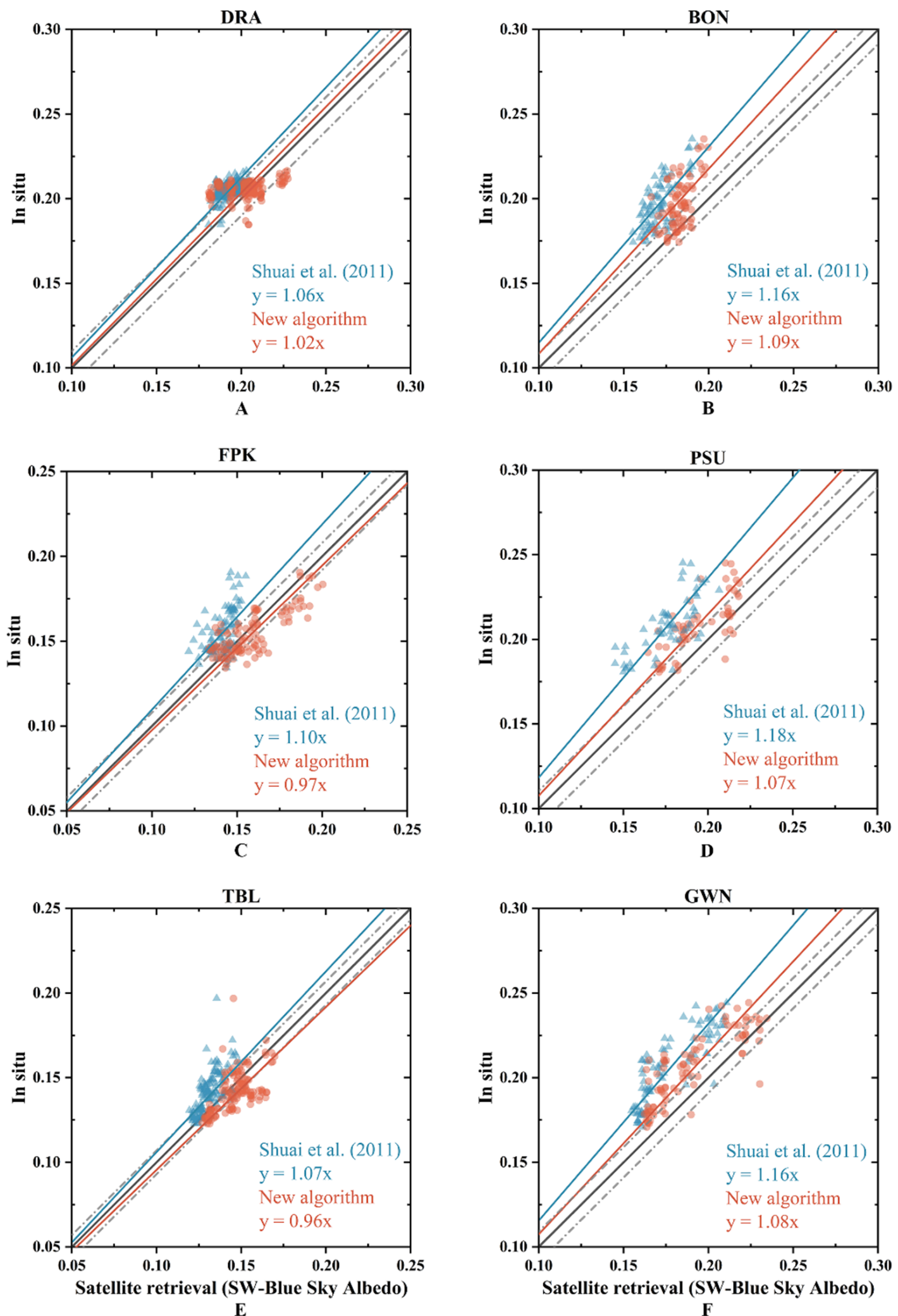

* In situ

$\triangle$ Shuai et al. (2011)

New algorithm

Figure 6. Validation of concurrent approach and new algorithm albedo products using in situ data from each site. Dotted gray lines indicate $5 \%$ uncertainty of each site, solid lines are one-to-one lines. The slopes of the fitted lines were obtained by the least square method, with intercepts of all the fitted lines set to 0. (A): Desert Rock (DRA); (B): Bondville (BON); (C): Fort Peck (FPK); (D): Penn State University (PSU); (E): Table Mountain (TBL); (F): Goodwin Creek (GWN). 
Table 5. Comparison between the Concurrent approach and New algorithm for albedo retrieval.

\begin{tabular}{|c|c|c|c|c|c|c|c|c|c|c|c|c|}
\hline \multirow{2}{*}{\multicolumn{2}{|c|}{ Site ID\# }} & \multirow[b]{2}{*}{ Samples } & \multicolumn{5}{|c|}{ Concurrent Approach } & \multicolumn{5}{|c|}{ New Algorithm } \\
\hline & & & RMSE & $\begin{array}{c}\text { Median } \\
\text { Deviation }\end{array}$ & $\begin{array}{c}\text { Mean } \\
\text { Bias }\end{array}$ & $\mathbf{R}^{2}$ & Slope & RMSE & $\begin{array}{c}\text { Median } \\
\text { Deviation }\end{array}$ & $\begin{array}{c}\text { Mean } \\
\text { Bias }\end{array}$ & $\mathbf{R}^{2}$ & Slope \\
\hline \multirow{3}{*}{$\mathrm{A}$} & DRA & 177 & 0.013 & -0.010 & -0.011 & 0.67 & 1.06 & 0.012 & 0.003 & -0.002 & 0.39 & 1.02 \\
\hline & FPK & 103 & 0.017 & -0.008 & -0.013 & 0.71 & 1.10 & 0.011 & 0.005 & 0.004 & 0.81 & 0.97 \\
\hline & TBL & 131 & 0.014 & -0.012 & -0.011 & 0.81 & 1.07 & 0.011 & 0.004 & 0.002 & 0.75 & 0.96 \\
\hline \multicolumn{2}{|c|}{ Representative sites } & 311 & 0.015 & -0.014 & -0.012 & 0.96 & 1.07 & 0.011 & 0.004 & 0.002 & 0.94 & 0.98 \\
\hline \multirow{3}{*}{ B } & $\mathrm{BON}$ & 83 & 0.029 & -0.026 & -0.027 & 0.74 & 1.16 & 0.018 & -0.013 & -0.014 & 0.61 & 1.09 \\
\hline & GWN & 89 & 0.030 & -0.033 & -0.029 & 0.84 & 1.16 & 0.019 & -0.021 & -0.015 & 0.83 & 1.08 \\
\hline & PSU & 31 & 0.034 & -0.032 & -0.032 & 0.81 & 1.18 & 0.020 & -0.016 & -0.015 & 0.82 & 1.07 \\
\hline \multicolumn{2}{|c|}{$\begin{array}{l}\text { Non-representative } \\
\text { sites }\end{array}$} & 206 & 0.032 & -0.032 & -0.030 & 0.77 & 1.18 & 0.020 & -0.019 & -0.015 & 0.78 & 1.09 \\
\hline \multicolumn{2}{|c|}{ All six sites } & 517 & 0.026 & -0.028 & -0.018 & 0.90 & 1.13 & 0.015 & -0.011 & -0.005 & 0.91 & 1.03 \\
\hline
\end{tabular}

Although the albedo retrieval for each representative site was in good agreement with the field measurements, the $\mathrm{R}^{2}$ for some sites were relatively abnormal (Table 5 ). The $R^{2}$ was relatively poor for representative site, such as DRA $\left(R^{2}=0.39\right)$. Conversely, the $R^{2}$ may have been higher for each non-representative site, such as GWN $\left(R^{2}=0.83\right)$. It is worth noting that $R^{2}$ would be very low even if the RMSE is small, if there is a weak linear relationship between satellite retrieval and ground data, or if the amount of data analyzed is small $[37,39]$. To reduce the impact, the data were analyzed using two groups: representative and non-representative sites, as shown in Table 5. The results of CAP and NP had high correlation coefficients at representative sites, 0.96 and 0.94 , and lower correlation coefficients at non-representative sites, 0.77 and 0.78 , with overall correlation coefficients of 0.90 and 0.91 . Therefore, the correlations between the two products and the ground measurements were similar.

Figure 7 shows the compared albedo retrieval results from the two algorithms for all sites and all ground measurements; after aggregation, the total number of samples was 85 . At all sites, the slopes from the new algorithm (Figure 7B) were closer to 1 than those of concurrent approach (Figure 7A). The overall RMSE decreased from $14 \%$ to $8 \%$, the median deviation dropped from -0.028 to -0.011 and the mean bias decreased from -0.018 to -0.005 . Therefore, the new algorithm has corrected the underestimation and improved the accuracy of albedo retrieval.

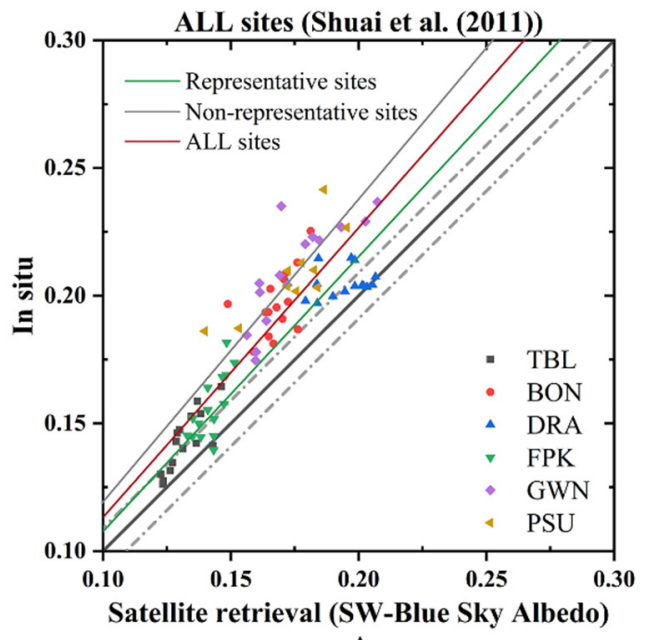

A

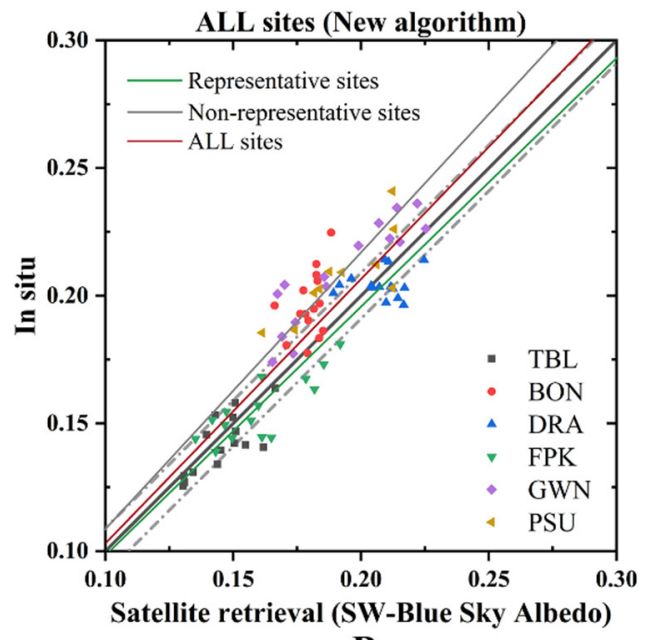

B

Figure 7. Results of albedo retrieval verified on all sites by concurrent approach (A), compared with results of albedo retrieval by the new algorithm (B). Dotted gray lines indicate $5 \%$ uncertainty of all sites, solid lines are one-to-one lines. The slopes of the fitted lines were obtained by the least square method, with intercepts of all the fitted lines set to 0 . Please refer to the Table 5 for the slopes of the fitted lines. 


\subsection{Comparison of Three Albedo Products}

Figure 8 shows the spatial patterns of the albedo in the $15 \times 15 \mathrm{~km}$ range of the GWN site on 9 April 2014. The albedos from these three products visually had similar spatial distributions in overall patterns, while the MODIS albedo smoothed tiny detail about the surface. Therefore, the two kinds of Landsat retrievals have the potential to finely describe tiny-scale natural surface detail in albedo.

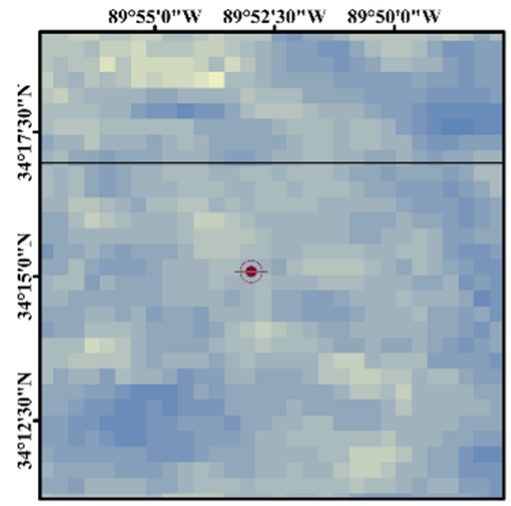

(A) MODIS

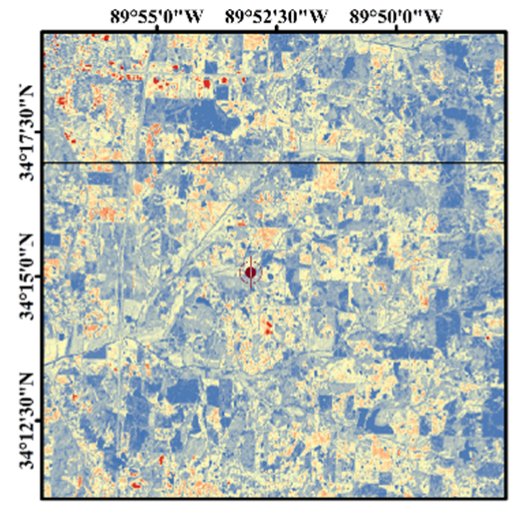

(B) Shuai et al.

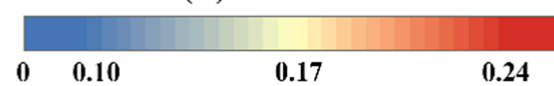

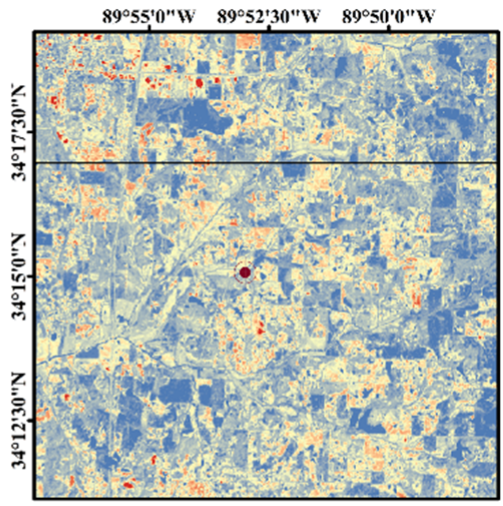

(C) New algorithm

Albedo

Figure 8. Black-sky albedo spatial distribution of 500-m MODIS at Landsat illumination (A), concurrent approach product (B), and new algorithm product (C) over a range of $15 \times 15 \mathrm{~km}$ at GWN on April 9, 2014. A dark red sign indicates the location of the Goodwin Creek (GWN) site.

Figure 9 shows the histograms of the three albedo products in Figure 8. Here, the standard deviation (Stdev) was used to quantify the magnitude of spatial heterogeneity between the MODIS product, CAP, and NP. Unsurprisingly, the standard deviations of both CAP and NP were significantly higher than that of MODIS albedo. The standard deviation of the MODIS product was 0.009 , while that of CAP and NP were 0.026 and 0.027 , respectively, indicating that the two finer albedo products had similar spatial heterogeneity.

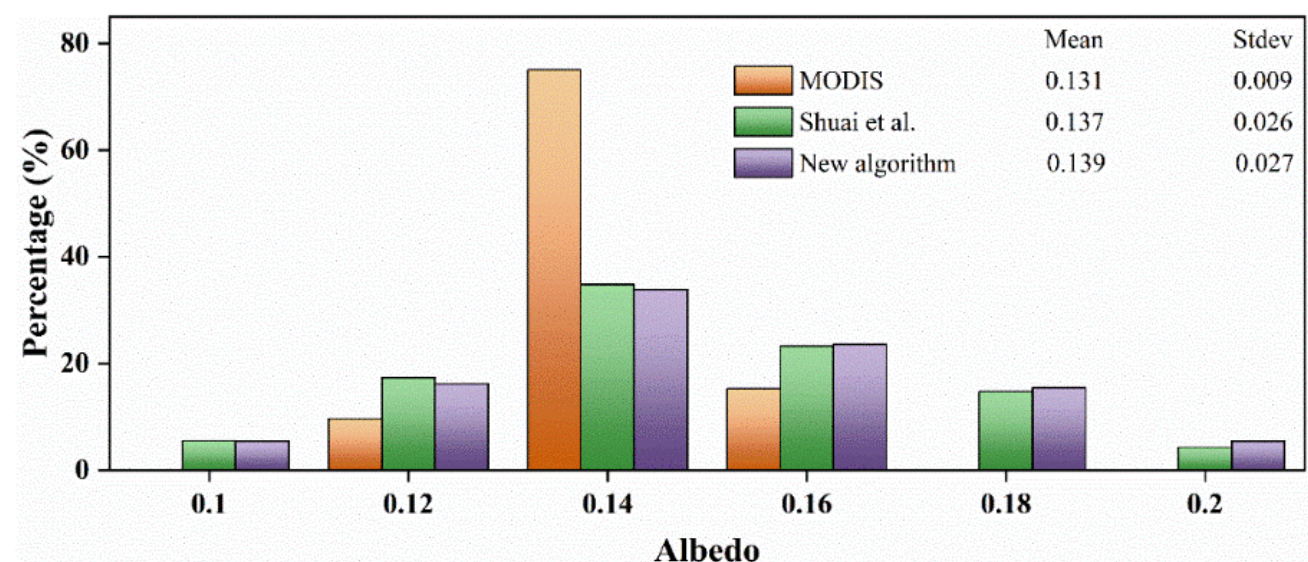

Figure 9. Histograms of the three black-sky albedo products shown in Figure 8.

To test the spatial characteristics of the three albedo products, a random transect line was graphed in Figure 8, from which the data were picked up for spatial characteristics analysis. The results implied that the Landsat albedo retrievals had a better spatial expression capability, because they were more dramatic and greater fluctuation than the MODIS product (Figure 10A). Figure 10B further qualitatively analyzes the spatial characteristics 
of three products. Obviously, the whiskers of NP albedo had greater range than other products, which further indicated that NP had better spatial expression capability.

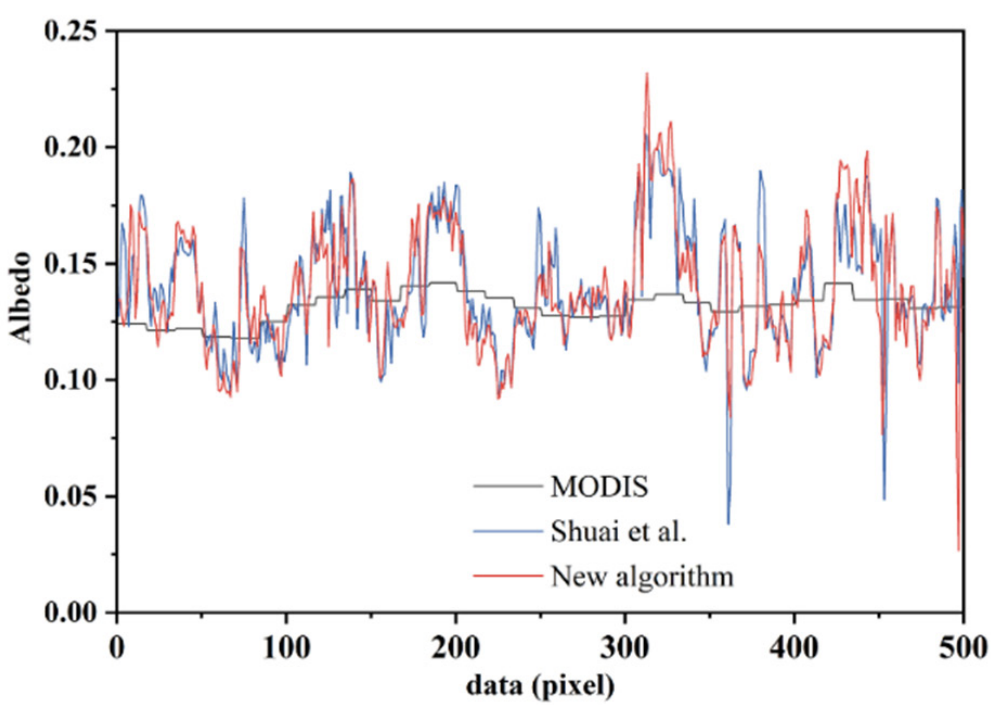

(A)

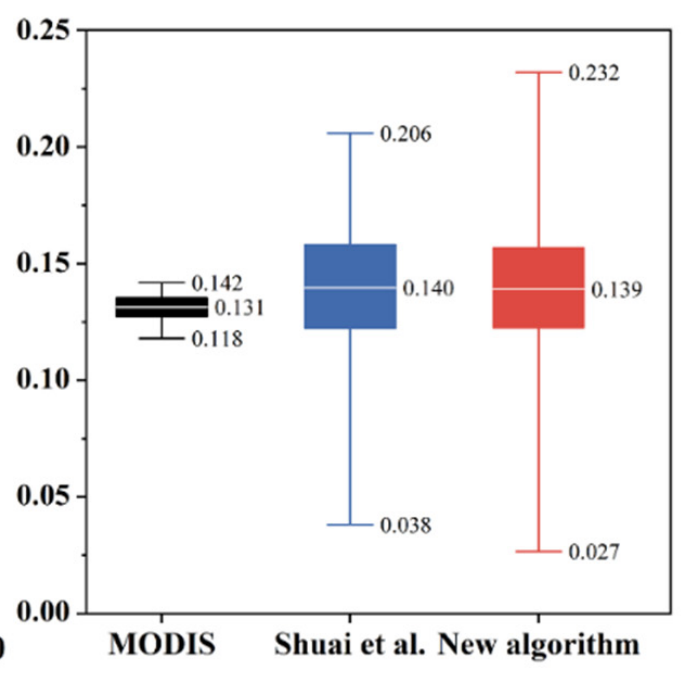

(B)

Figure 10. Comparison between the land surface albedos from the three datasets along a transect (black lines in Figure 8). (A): the cross-sectional view of the three products; (B): the boxplots of three albedo products. The whiskers represent the maximum and minimum value of statistics.

\subsection{Capture Daily Surface Dynamics}

Although a finer resolution of surface albedo has been derived to describe fragmented details, the 16-day Landsat reflectance makes it difficult to capture surface dynamics, especially in the growing and senescent seasons, which are of vital importance in monitoring the seasonal characteristics of climate change. The new algorithm in this study generated a synthetic 30-m high temporal-spatial resolution albedo to solve this problem. In the growing season of GWN, we differentiated between the inversion results from 9 April 2014 and that from adjacent dates to identify daily changes in black-sky albedo in the $15 \times 15 \mathrm{~km}$ range (Figure 11). As the new algorithm modulated albedo values, the significant variations in albedo (difference $>0.01$ ) were captured (Figure 11a-l; Figure 11c-p). We calculated the daily mean albedo of the two products and the spatial correlation between two products' variation in the eight days as shown in Table 6. The results indicated that NP not only reflected the daily albedo change such as MODIS with $\mathrm{R}^{2}$ higher than 0.7 , but also described the range of change more finely.

Table 6. Statistical results of the mean albedo of the two products, and the correlation between two products' variation in the eight days adjacent to 9 April 2014 at GWN (Figure 11).

\begin{tabular}{ccccccccc}
\hline Date & $\mathbf{0 4 / 0 5}$ & $\mathbf{0 4 / 0 6}$ & $\mathbf{0 4 / 0 7}$ & $\mathbf{0 4 / 0 8}$ & $\mathbf{0 4 / 1 0}$ & $\mathbf{0 4 / 1 1}$ & $\mathbf{0 4 / 1 2}$ & $\mathbf{0 4 / 1 3}$ \\
\hline MODIS mean albedo & 0.131 & 0.131 & 0.131 & 0.131 & 0.133 & 0.133 & 0.134 & 0.134 \\
Landsat mean albedo & 0.138 & 0.139 & 0.139 & 0.139 & 0.140 & 0.140 & 0.141 & 0.142 \\
$\mathrm{R}^{2}$ & 0.76 & 0.87 & 0.87 & 0.86 & 0.81 & 0.79 & 0.71 & 0.71 \\
\hline
\end{tabular}




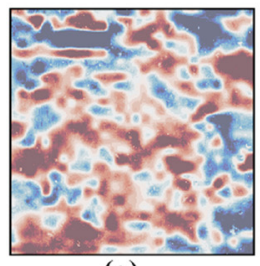

(a)

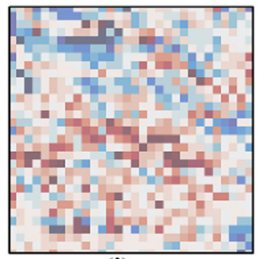

(i)

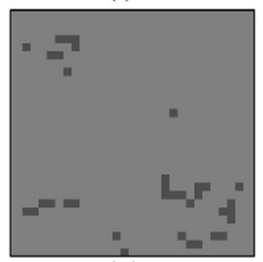

(q)

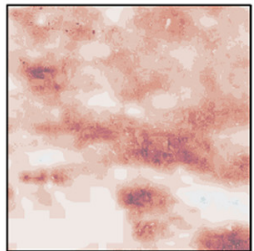

(e)

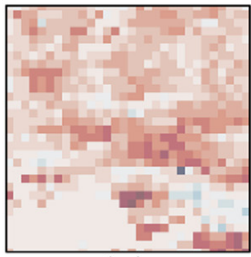

(m)

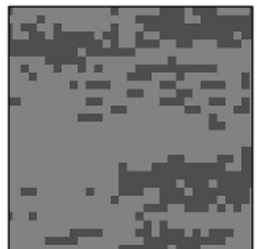

(u)

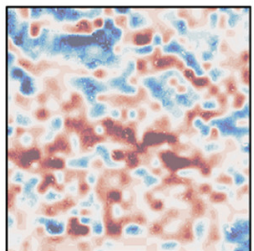

(b)

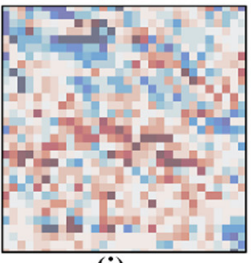

(j)

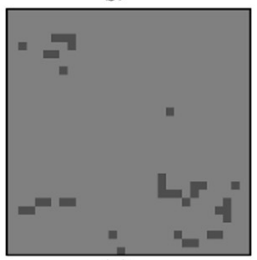

(r)

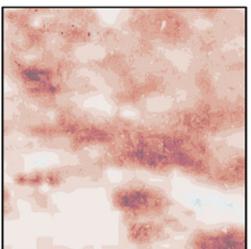

(f)

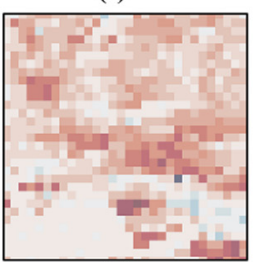

(n)

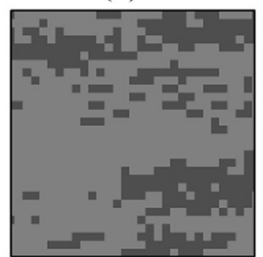

(v)

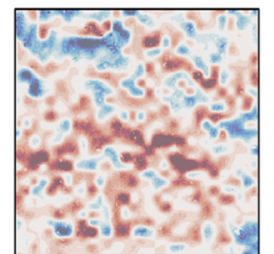

(c)

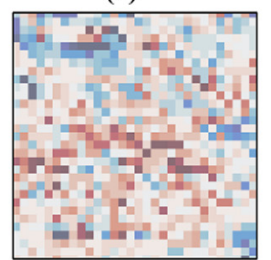

(k)

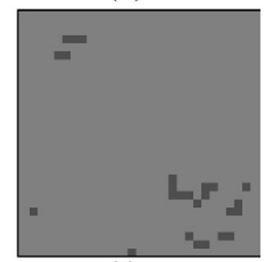

(s)

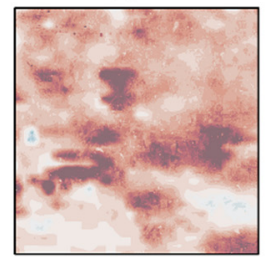

(g)

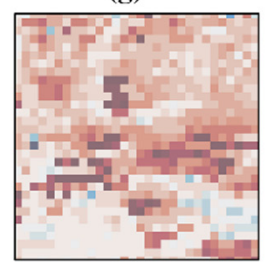

(o)

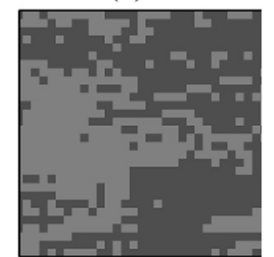

(w)

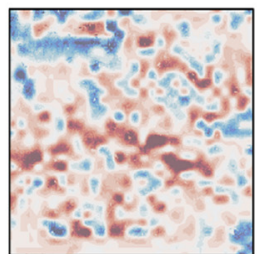

(d)

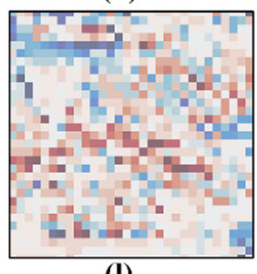

(I)

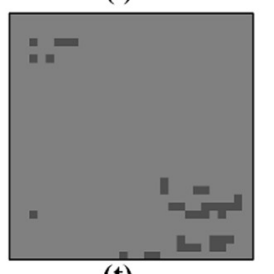

(t)

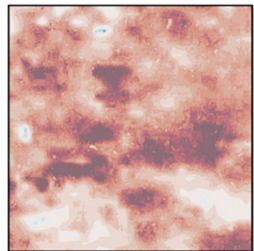

(h)

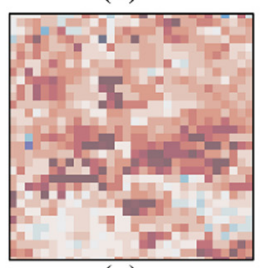

(p)

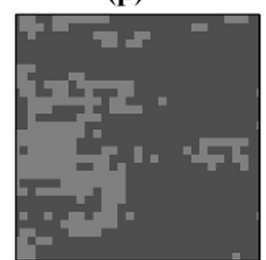

(x)

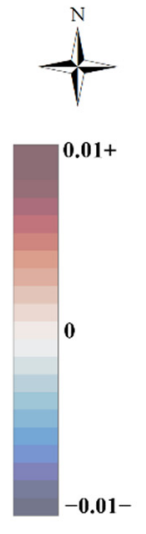

Full BRDF Inversions

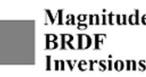

Inversion

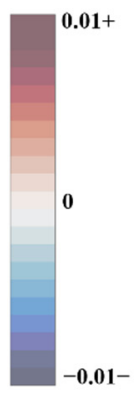

Full BRDF Inversions

Magnitude

BRDF

Inversion

Figure 11. (a-h) depict the difference distributions of black-sky new albedo products from 9 April 2014 and that from adjacent dates (5th, 6th, 7th, 8th, 10th, 11th, 12th, and 13th of April 2014), respectively, in the $15 \times 15 \mathrm{~km}$ range at Goodwin Creek (GWN). (i-p) show the corresponding difference distributions in MODIS black-sky albedo. Red depicts areas with higher albedo than 9 April 2014 , and blue shows the opposite. (q-x) depict the corresponding quality marks of MODIS albedo.

\section{Discussion}

\subsection{Performance Evaluation and Seasonal Deviation Analysis}

High temporal-spatial resolution albedo is helpful for understanding the relationship between surface energy balances, vegetation cover dynamics, and ecosystem disturbance. In this study, NP had a lower uncertainty (RMSE of $8 \%$ ) than CAP (RMSE of $14 \%$ ), which was approaching the requirement of the World Meteorological Organization (5\%) [17]. Therefore, NP had favorable usability and robustness to produce high spatial-temporal resolution albedo. 
Similar to previous retrieval results using the concurrent approach [37,39], CAP was underestimated at all sites, compared with field measurements (Table 5). The deviation is mainly due to the underestimation of dormant albedo at non-representative sites. The reason could be that the single-type composition of these sites still contained a variety of soil conditions (such as soil moisture, soil hardness, and planting types) [39,45]. In addition, the fragmented vegetation at these sites is dominated by human disturbance events, because the GWN site is covered with pasture, and both BON and PSU are agricultural research fields. This means that albedo decreases rapidly after crops are planted and increases rapidly after the crops are harvested. For these non-representative areas, the single-type anisotropy information collected by the concurrent approach contains a variety of other vegetation information, which hinders the accurate determination of BRDFs [45]. Therefore, in these complex areas where land cover changes faster or slower than the average rate of land cover in single type, seasonal deviations are likely to occur.

Fortunately, because the new algorithm incorporates the addition of prior NIR AFX [79] and NIR AN ratio [37] in spatial differences, these complicated areas could be further distinguished into combinations of various homogeneous surfaces, so that the seasonal deviations were taken into account in an improved way. The retrieval errors have been limited to each 500-m grid by the use of prior knowledge, instead of accumulating with changes in spatial position. Therefore, the new method has shown favorable retrieval capabilities at all sites, especially for those that are non-representative.

\subsection{Spatial Heterogeneity}

Regarding the spatial heterogeneity of three albedo products, Landsat albedo products were significantly higher than that of MODIS (Figure 9). Especially, NP had better spatial expression capability (Figure 10B). However, there was a consistent mismatch of mean albedo among the MODIS albedo and NP in the extended heterogeneous area of GWN (Table 6). According to Cescatti et al. [84], MODIS albedo retrievals for non-forested land underestimate the field measurements of the entire seasonal cycle. This mismatch is likely due to the extreme fragmentation of these landscapes [84].

\subsection{Quality Control Suggestions and Limitations}

Surface albedo is sensitive to atmospheric conditions, which the synthetic albedo products cannot control the quality of albedo at simulated illuminations. Although MODIS quality markers cannot describe the atmospheric conditions under the specific simulated illumination of Landsat, data from multiple samples taken at different times gives a better picture of the day's weather. Additionally, the reliability of these variations depends on MODIS albedo quality markers (Figure 11C), because the modulation term $C_{S W}$ at MODIS scale is limited by the quality of satellite acquisitions [20]. Therefore, we suggested to use both MODIS quality markers and BRDF inversion markers for the 30-m albedo quality control to obtain the high-quality albedo.

In agricultural areas of GWN, spatial variations in albedo may be caused by crop growth, human disturbance, or small-scale microclimates [40]. As a result, these finer resolution albedo images not only captured details of surface heterogeneity, but also reflected the small-scale changes in albedo caused by variations in surface conditions, which is helpful for monitoring continuous small-scale changes in albedo (e.g., vegetation phenology, fire, snow, and melt). Further study is needed to extend this study to different land cover over a longer time-series, to accurately obtain the seasonal characteristics of heterogeneous ground.

\subsection{Other Sources of Errors and Potential Improvements}

There are potential random and systematic errors in data processing, mainly caused by MODIS/Landsat scale conversions and narrow-to-broad band conversion. Here, we focused on the errors of the MODIS/Landsat scale conversions. First, it retrieves favorable results for Landsat albedo, using NIR AFX and NIR AN ratio as a connection between 
Landsat and MODIS at different scales, to convert heterogeneous surfaces into appropriate pure pixel values. Although using these two types of prior knowledge can most effectively produce appropriate information for ground objects, outputs may be incorrect for some land surfaces, because the properties of some 30-m surfaces may not fall within the 500-m resolution of information provided by high-quality BRDF. Therefore, further research on these specific land surfaces is needed, to find a more reliable retrieval method that suits them. Second, although the simplified data fusion method can bypass the need to convert multi-band spectral response functions and capture variations in albedo, the modulated results might be unreliable because the 500-m smooth modulation term, $C$, may not match fragmented Landsat patches. Hence, a more advanced method is required to reasonably disaggregate the $500-\mathrm{m}$ modulation term, $C$, to a $30-\mathrm{m}$ resolution.

In addition, we note that another potential source of errors in albedo retrieval may be the algorithm itself. With regard to the studies on validating albedo at ground observation stations, the albedo retrieved by the kernel-driven model has generally lower values than those from in situ site measurements [62,75]. Liu et al. [60] pointed out that with increases in SZA, the negative deviation and RMSE of the albedo retrieval results from the kernel-driven model increase. This means that the uncertainties in albedo retrieval might be related to the SZA through the kernel-driven model. In this study, because Landsat's observation zenith angle and relative azimuth angle are both set to 0 to simplify the calculation, the value of the volume scattering kernel is always zero, which would result in erroneous BRF calculations for some SZAs via the kernel-driven model. Therefore, using the kernel-driven model to calculate the AN ratio might produce inaccuracies for some SZAs, causing systematic errors in the retrieval results. Further study is needed to validate the reliability of AN ratio.

Practical solutions can reduce procedural difficulties and errors. In the Landsat $180 \times 180 \mathrm{~km}$ scene range, using prior knowledge could reduce the number of pure pixels that meet requirements or even lead to retrieval failure. To increase the possibility of pure pixels being identified, $\mathrm{Li}$ et al. [46] suggested that multiple adjacent images collected on the same day should be mosaicked to increase the chance of finding these pure pixels. It is also possible to couple VIIRS BRDF with Landsat surface reflectance, and then select for qualified VIIRS pure pixels to improve the quality of albedo retrievals [46]. Additionally, terrain effects can cause distortion of the reflection shape and hemispherical distribution, thereby affecting surface reflectivity [85]. In future research, a three-dimensional kerneldriven model could be used to reduce the impact of terrain effects on albedo retrieval.

\section{Conclusions}

This study proposed a new method for estimating Landsat albedo by coupling MODIS BRDF and Landsat- 8 surface reflectance. These efforts have been verified at six SURFRAD sites, and the main conclusions are the following:

- The results demonstrated that the new method had favorable usability and robustness, with less uncertainty (RMSE of 0.015 [8\%]), less offset (mean bias of -0.005 ), and better accuracy (median deviation of -0.011) than CAP. In particular, the RMSE for non-representative sites was significantly improved, mainly by corrections for seasonal deviations.

- The new method can limit the seasonal deviations and capture subtle changes in surface albedo of an extended heterogeneous surface. As a result, the new method expands the capacity to retrieve albedo for complex heterogeneous surfaces, because the retrieval errors have been limited to each 500 -m grid by prior BRDF knowledge, instead of accumulating with changes in spatial position.

- The new Landsat albedo product can accurately, finely, and continuously reveal more dynamic surface information. In addition, this simple operability could enable users to continuously and accurately retrieve albedo products with high spatial and temporal resolution in the absence of other auxiliary data (such as topography, land cover types, 
or disturbance of nature). Therefore, the new method is quite practical and thus very attractive.

Future work will be devoted to the additional verification of Landsat albedo products for different types of surface areas over a longer period, and consider the impact of topographical effects.

Author Contributions: Conceptualization, G.Y., J.X. and J.W.; methodology, G.Y.; software, G.Y.; validation, J.X. and G.Y.; formal analysis, G.Y., J.W., Z.Y. and C.Y.; investigation, G.Y.; resources, G.Y.; data curation, G.Y. and H.S.; writing—original draft preparation, G.Y.; writing-review and editing, J.X., J.W., J.L., Y.D., Y.H. and W.H.; visualization, G.Y., C.Y., Z.Y. and H.S.; supervision, J.X. and J.W.; project administration, J.X. and J.W.; funding acquisition, J.X. All authors have read and agreed to the published version of the manuscript.

Funding: This study is supported by Key R\&D project of Sichuan Science and Technology Department (Grant No. 2021YFQ0042), Strategic Priority Research Program of the Chinese Academy of Sciences (Grant No. XDA20030302), National Flash Flood Investigation and Evaluation Project (Grant No. SHZHIWHR-57), National Key R\&D Program of China (2020YFD1100701), and the Science and Technology Project of Xizang Autonomous Region (Grant No. XZ201901-GA-07), Project from the Science and Technology Bureau of Altay Region in Yili Kazak Autonomous Prefecture. The authors are grateful to this support.

Institutional Review Board Statement: Not applicable.

Informed Consent Statement: Not applicable.

Data Availability Statement: The MODIS BRDF/Albedo data (Collection 6) were downloaded from the LPDAAC of the US NASA and USGS partnership (https:/ /lpdaac.usgs.gov). The Landsat data were obtained from the USGS Earth Resources Observation and Science (EROS) Center Science Processing Architecture (ESPA) (https://espa.cr.usgs.gov). Thanks to NOAA SURFARD for the field albedo measurements (https://gml.noaa.gov/grad/surfrad/index.html). Images of the six ground sites used in this study were acquired from high-resolution satellite data on https://www.google.com/earth.

Conflicts of Interest: The authors declare no conflict of interest.

$\begin{array}{ll}\text { Abbreviations } & \\ \text { The following abbreviations are used in this article: } \\ \text { AFX } & \text { Anisotropic Flat Index } \\ \text { AN ratio } & \text { Albedo-to-Nadir reflectance ratio } \\ \text { AVIRIS } & \text { Airborne Visible-InfraRed Imaging Spectrometer } \\ \text { BON } & \text { Bondville site } \\ \text { BRDF } & \text { Bidirectional Reflectance Distribution Function } \\ \text { BSA } & \text { Black-Sky Albedo } \\ \text { CAP } & \text { Concurrent Approach Product } \\ \text { DRA } & \text { Desert Rock site } \\ \text { EROS } & \text { Earth Resources Observation and Science } \\ \text { ESPA } & \text { EROS Processing Architecture } \\ \text { FPK } & \text { Fort Peck site } \\ \text { GWN } & \text { Goodwin Creek site } \\ \text { ISO data analysis } & \text { Iterative Self-Organizing data analysis } \\ \text { LaSRC } & \text { Land Surface Reflectance Code } \\ \text { LSN } & \text { Local Solar Noon } \\ \text { LUT } & \text { Look-Up Table } \\ \text { MODIS } & \text { MODerate Resolution Imaging Spectroradiometer } \\ \text { NASA } & \text { National Aeronautics and Space Administration } \\ \text { NIR } & \text { Near-infrared } \\ \text { NP } & \text { New albedo Product } \\ \text { NTB } & \text { Narrowband-to-Broadband } \\ \text { POLDER } & \text { Polarization and Directionality of the Earth Reflectance } \\ \end{array}$




$\begin{array}{ll}\text { PROBA-V } & \text { PROBA-VEGETATION } \\ \text { PSU } & \text { Penn State University site } \\ \text { RMSE } & \text { Root Mean Square Error } \\ \text { RSR } & \text { Relative Spectral Response } \\ \text { SEVIRI } & \text { Spinning Enhanced Visible and Infrared Imagers } \\ \text { STARFM } & \text { Spatial and Temporal Adaptive Reflectance Fusion Model } \\ \text { SURFRAD } & \text { Surface Radiation budget network } \\ \text { SW } & \text { Short-wave } \\ \text { SZA } & \text { Solar Zenith Angle } \\ \text { TBL } & \text { Table Mountain site } \\ \text { USGS } & \text { United States Geological Survey } \\ \text { VGT } & \text { VEGETATION } \\ \text { VIIRS } & \text { Visible Infrared Imaging Radiometer Suite } \\ \text { WSA } & \text { White-Sky Albedo }\end{array}$

\section{References}

1. Dickinson, R.E. Land surface processes and climate-Surface albedos and energy balance. Adv. Geophys. 1983, 25, 305-353. [CrossRef]

2. Dickinson, R.E. Land processes in climate models. Remote Sens. Environ. 1995, 51, 27-38. [CrossRef]

3. Wang, S.; Davidson, A. Impact of climate variations on surface albedo of a temperate grassland. Agric. For. Meteorol. 2007, 142, 133-142. [CrossRef]

4. Trenberth, K.E.; Fasullo, J.T.; Kiehl, J. Earth's global energy budget. Bull. Am. Meteorol. Soc. 2009, 90, 311-323. [CrossRef]

5. Loarie, S.R.; Lobell, D.B.; Asner, G.P.; Mu, Q.; Field, C.B. Direct impacts on local climate of sugar-cane expansion in Brazil. Nat. Clim. Chang. 2011, 1, 105-109. [CrossRef]

6. Govaerts, Y.M.; Lattanzio, A.; Taberner, M.; Pinty, B. Generating global surface albedo products from multiple geostationary satellites. Remote Sens. Environ. 2008, 112, 2804-2816. [CrossRef]

7. He, T.; Liang, S.; Yu, Y.; Wang, D.; Gao, F.; Liu, Q. Greenland surface albedo changes in July 1981-2012 from satellite observations. Environ. Res. Lett. 2013, 8, 044043. [CrossRef]

8. Alibakhshi, S.; Naimi, B.; Hovi, A.; Crowther, T.W.; Rautiainen, M. Quantitative analysis of the links between forest structure and land surface albedo on a global scale. Remote Sens. Environ. 2020, 246, 111854. [CrossRef]

9. Ye, S.; Feng, H.; Zou, B.; Ding, Y.; Zhu, S.; Li, F.; Dong, G. Satellite-based estimation of the influence of land use and cover change on the surface shortwave radiation budget in a humid basin. Remote Sens. 2021, 13, 1447. [CrossRef]

10. An, Y.; Meng, X.; Zhao, L.; Li, Z.; Wang, S.; Shang, L.; Chen, H.; Lyu, S.; Li, G.; Ma, Y. Performance of GLASS and MODIS Satellite Albedo products in diagnosing Albedo variations during different time scales and special weather conditions in the Tibetan Plateau. Remote Sens. 2020, 12, 2456. [CrossRef]

11. Cierniewski, J.; Roujean, J.L.; Jasiewicz, J.; Królewicz, S. Seasonal net shortwave radiation of bare arable land in Poland and Israel according to roughness and atmospheric irradiance. Remote Sens. 2021, 13, 1897. [CrossRef]

12. Chen, C.; Tian, L.; Zhu, L.; Zhou, Y. The Impact of Climate Change on the Surface Albedo over the Qinghai-Tibet Plateau. Remote Sens. 2021, 13, 2336. [CrossRef]

13. Carrer, D.; Ceamanos, X.; Roujean, J.L. Analysis of snow-free vegetation and bare soil albedos and application to numerical weather prediction. Int. Geosci. Remote Sens. Symp. 2013, 3789-3792. [CrossRef]

14. Betts, R.A. Offset of the potential carbon sink from boreal forestation by decreases in surface albedo. Nature 2000, 408, 187-190. [CrossRef]

15. Sellers, P.J.; Meeson, B.W.; Hall, F.G.; Asrar, G.; Murphy, R.E.; Schiffer, R.A.; Bretherton, F.P.; Dickinson, R.E.; Ellingson, R.G.; Field, C.B.; et al. Remote sensing of the land surface for studies of global change: Models-algorithms-experiments. Remote Sens. Environ. 1995, 51, 3-26. [CrossRef]

16. Fletcher, C.G.; Kushner, P.J.; Hall, A.; Qu, X. Circulation responses to snow albedo feedback in climate change. Geophys. Res. Lett. 2009, 36, 2-5. [CrossRef]

17. Bayat, C.B. GCOS The Global Observing System For Climate Implementation Needs. World Meteorol. Organ. 2016, $200,316$.

18. Lucht, W.; Schaaf, C.B.; Strahler, A.H. An algorithm for the retrieval of albedo from space using semiempirical BRDF models. IEEE Trans. Geosci. Remote Sens. 2000, 38, 977-998. [CrossRef]

19. Li, X.; Gao, F.; Wang, J.; Strahler, A. A priori knowledge accumulation and its application to linear BRDF model inversion. J. Geophys. Res. Atmos. 2001, 106, 925-935. [CrossRef]

20. Schaaf, C.B.; Gao, F.; Strahler, A.H.; Lucht, W.; Li, X.; Tsang, T.; Strugnell, N.C.; Zhang, X.; Jin, Y.; Muller, J.; et al. First operational BRDF, albedo nadir reflectance products from MODIS. Remote Sens. Environ. 2002, 83, 135-148. [CrossRef]

21. Pokrovsky, O.; Roujean, J.L. Land surface albedo retrieval via kernel-based BRDF modeling: I. Statistical inversion method and model comparison. Remote Sens. Environ. 2003, 84, 100-119. [CrossRef]

22. Maignan, F.; Bréon, F.M.; Lacaze, R. Bidirectional reflectance of Earth targets: Evaluation of analytical models using a large set of spaceborne measurements with emphasis on the Hot Spot. Remote Sens. Environ. 2004, 90, 210-220. [CrossRef] 
23. Liu, Y.; Wang, Z.; Sun, Q.; Erb, A.M.; Li, Z.; Schaaf, C.B.; Zhang, X.; Román, M.O.; Scott, R.L.; Zhang, Q.; et al. Evaluation of the VIIRS BRDF, Albedo and NBAR products suite and an assessment of continuity with the long term MODIS record. Remote Sens. Environ. 2017, 201, 256-274. [CrossRef]

24. He, T.; Liang, S.; Wang, D.; Shi, Q.; Tao, X. Estimation of high-resolution land surface shortwave albedo from AVIRIS data. IEEE J. Sel. Top. Appl. Earth Obs. Remote Sens. 2014, 7, 4919-4928. [CrossRef]

25. Dominique, C.; Bruno, S.; Xavier, C.; Jean-Louis, R.; Roselyne, L. Copernicus Global Land Operations Vegetation and Energy CGLOPS-1, Framework Service Contract 199494; Algorithm Theoretical Basis Document, Issue 2.11. 2018. Available online: https:/ /land.copernicus.eu/global/sites/cgls.vito.be/files/products/CGLOPS_ATBD_SA1km-V1_I2.11.pdf (accessed on 13 October 2021).

26. Sánchez-Zapero, J.; Camacho, F.; Martínez-Sánchez, E.; Lacaze, R.; Carrer, D.; Pinault, F.; Benhadj, I.; Muñoz-Sabater, J. Quality assessment of PROBA-V surface Albedo V1 for the continuity of the copernicus climate change service. Remote Sens. 2020, $12,2596$. [CrossRef]

27. Carrer, D.; Moparthy, S.; Lellouch, G.; Ceamanos, X.; Pinault, F.; Freitas, S.C.; Trigo, I.F. Land surface albedo derived on a ten daily basis from Meteosat Second Generation Observations: The NRT and climate data record collections from the EUMETSAT LSA SAF. Remote Sens. 2018, 10, 1262. [CrossRef]

28. Amazirh, A.; Bouras, E.H.; Olivera-Guerra, L.E.; Er-Raki, S.; Chehbouni, A. Retrieving crop albedo based on radar sentinel-1 and random forest approach. Remote Sens. 2021, 13, 3181. [CrossRef]

29. Kuusinen, N.; Stenberg, P.; Korhonen, L.; Rautiainen, M.; Tomppo, E. Structural factors driving boreal forest albedo in Finland. Remote Sens. Environ. 2016, 175, 43-51. [CrossRef]

30. Wang, Z.; Erb, A.M.; Schaaf, C.B.; Sun, Q.; Liu, Y.; Yang, Y.; Shuai, Y.; Casey, K.A.; Román, M.O. Early spring post-fire snow albedo dynamics in high latitude boreal forests using Landsat-8 OLI data. Remote Sens. Environ. 2016, 185, 71-83. [CrossRef]

31. Traversa, G.; Fugazza, D.; Senese, A.; Frezzotti, M. Landsat 8 oli broadband albedo validation in antarctica and greenland. Remote Sens. 2021, 13, 799. [CrossRef]

32. Ren, S.; Miles, E.S.; Jia, L.; Menenti, M.; Kneib, M.; Buri, P.; McCarthy, M.J.; Shaw, T.E.; Yang, W.; Pellicciotti, F. Anisotropy parameterization development and evaluation for glacier surface albedo retrieval from satellite observations. Remote Sens. 2021, 13, 1714. [CrossRef]

33. Kimes, D.S.; Sellers, P.J. Inferring hemispherical reflectance of the earth's surface for global energy budgets from remotely sensed nadir or directional radiance values. Remote Sens. Environ. 1985, 18, 205-223. [CrossRef]

34. Gao, F.; He, T.; Masek, J.G.; Shuai, Y.; Schaaf, C.B.; Wang, Z. Angular effects and correction for medium resolution sensors to support crop monitoring. IEEE J. Sel. Top. Appl. Earth Obs. Remote Sens. 2014, 7, 4480-4489. [CrossRef]

35. Barnsley, M.J.; Strahler, A.H.; Morris, K.P.; Muller, J.P. Sampling the surface bidirectional reflectance distribution function (BRDF): 1. Evaluation of current and future satellite sensors. Remote Sens. Rev. 1994, 8, 271-311. [CrossRef]

36. Plummer, S.; Lecomte, P.; Doherty, M. The ESA Climate Change Initiative (CCI): A European contribution to the generation of the Global Climate Observing System. Remote Sens. Environ. 2017, 203, 2-8. [CrossRef]

37. Shuai, Y.; Masek, J.G.; Gao, F.; Schaaf, C.B. An algorithm for the retrieval of 30-m snow-free albedo from Landsat surface reflectance and MODIS BRDF. Remote Sens. Environ. 2011, 115, 2204-2216. [CrossRef]

38. Zhang, K.; Zhou, H.; Wang, J.; Xue, H. Estimation and validation of high temporal and spatial resolution albedo. Int. Geosci. Remote Sens. Symp. 2013, 2888-2891. [CrossRef]

39. Franch, B.; Vermote, E.F.; Claverie, M. Intercomparison of Landsat albedo retrieval techniques and evaluation against in situ measurements across the US SURFRAD network. Remote Sens. Environ. 2014, 152, 627-637. [CrossRef]

40. Gao, B.; Gong, H.; Wang, T. A method for retrieving daily land surface albedo from space at 30-m resolution. Remote Sens. 2015, 7, 10951-10972. [CrossRef]

41. Zhang, X.; Guo, J.; Xie, R.; Jiao, Z.; Dong, Y.; He, T.; Ding, A.; Yin, S.; Zhang, H.; Cui, L.; et al. Development of the Direct-Estimation Albedo Algorithm for Snow-Free Landsat TM Albedo Retrievals Using Field Flux Measurements. IEEE Trans. Geosci. Remote Sens. 2020, 58, 1550-1567. [CrossRef]

42. Wang, Z.; Schaaf, C.B.; Sun, Q.; Kim, J.H.; Erb, A.M.; Gao, F.; Román, M.O.; Yang, Y.; Petroy, S.; Taylor, J.R.; et al. Monitoring land surface albedo and vegetation dynamics using high spatial and temporal resolution synthetic time series from Landsat and the MODIS BRDF/NBAR/albedo product. Int. J. Appl. Earth Obs. Geoinf. 2017, 59, 104-117. [CrossRef] [PubMed]

43. Kuusinen, N.; Tomppo, E.; Shuai, Y.; Berninger, F. Effects of forest age on albedo in boreal forests estimated from MODIS and Landsat albedo retrievals. Remote Sens. Environ. 2014, 145, 145-153. [CrossRef]

44. Abera, T.A.; Heiskanen, J.; Pellikka, P.K.E.; Adhikari, H.; Maeda, E.E. Climatic impacts of bushland to cropland conversion in Eastern Africa. Sci. Total Environ. 2020, 717, 137255. [CrossRef] [PubMed]

45. Roman, M.O.; Gatebe, C.K.; Shuai, Y.; Wang, Z.; Gao, F.; Masek, J.G.; He, T.; Liang, S.; Schaaf, C.B. Use of in situ and airborne multiangle data to assess MODIS- and landsat-based estimates of directional reflectance and albedo. IEEE Trans. Geosci. Remote Sens. 2013, 51, 1393-1404. [CrossRef]

46. Li, Z.; Erb, A.; Sun, Q.; Liu, Y.; Shuai, Y.; Wang, Z.; Boucher, P.; Schaaf, C. Preliminary assessment of 20-m surface albedo retrievals from sentinel-2A surface reflectance and MODIS/VIIRS surface anisotropy measures. Remote Sens. Environ. 2018, 217, 352-365. [CrossRef] 
47. Strugnell, N.C.; Lucht, W. An algorithm to infer continental-scale Albedo from AVHRR data, land over class, and field observation of typical BRDFs. J. Clim. 2001, 14, 1360-1376. [CrossRef]

48. Strugnell, N.C.; Lucht, W.; Schaaf, C. A global albedo data set derived from AVHRR data for use in climate simulations. Geophys. Res. Lett. 2001, 28, 191-194. [CrossRef]

49. Jiao, Z.; Zhang, H.; Dong, Y.; Liu, Q.; Xiao, Q.; Li, X. An algorithm for retrieval of surface Albedo from small view-angle airborne observations through the use of brdf archetypes as prior knowledge. IEEE J. Sel. Top. Appl. Earth Obs. Remote Sens. 2015, 8 , 3279-3293. [CrossRef]

50. Zhang, H.; Liu, P.; He, L.; Lian, Y.; Cui, T. Effects of reflectance anisotropy on albedo retrieval from satellite observations. Int. Geosci. Remote Sens. Symp. 2017, 2017, 3144-3154. [CrossRef]

51. Gao, F.; Masek, J.; Schwaller, M.; Hall, F. On the blending of the landsat and MODIS surface reflectance: Predicting daily landsat surface reflectance. IEEE Trans. Geosci. Remote Sens. 2006, 44, 2207-2218. [CrossRef]

52. Roy, D.P.; Ju, J.; Lewis, P.; Schaaf, C.; Gao, F.; Hansen, M.; Lindquist, E. Multi-temporal MODIS-Landsat data fusion for relative radiometric normalization, gap filling, and prediction of Landsat data. Remote Sens. Environ. 2008, 112, 3112-3130. [CrossRef]

53. Hilker, T.; Wulder, M.A.; Coops, N.C.; Linke, J.; McDermid, G.; Masek, J.G.; Gao, F.; White, J.C. A new data fusion model for high spatial- and temporal-resolution mapping of forest disturbance based on Landsat and MODIS. Remote Sens. Environ. 2009, 113, 1613-1627. [CrossRef]

54. Zurita-Milla, R.; Kaiser, G.; Clevers, J.G.P.W.; Schneider, W.; Schaepman, M.E. Downscaling time series of MERIS full resolution data to monitor vegetation seasonal dynamics. Remote Sens. Environ. 2009, 113, 1874-1885. [CrossRef]

55. Zhu, X.; Chen, J.; Gao, F.; Chen, X.; Masek, J.G. An enhanced spatial and temporal adaptive reflectance fusion model for complex heterogeneous regions. Remote Sens. Environ. 2010, 114, 2610-2623. [CrossRef]

56. Roy, D.P.; Zhang, H.K.; Ju, J.; Gomez-Dans, J.L.; Lewis, P.E.; Schaaf, C.B.; Sun, Q.; Li, J.; Huang, H.; Kovalskyy, V. A general method to normalize Landsat reflectance data to nadir BRDF adjusted reflectance. Remote Sens. Environ. 2016, 176, $255-271$. [CrossRef]

57. Liang, S.; Fang, H.; Chen, M.; Shuey, C.J.; Walthall, C.; Daughtry, C.; Morisette, J.; Schaaf, C.; Strahler, A. Validating MODIS land surface reflectance and albedo products: Methods and preliminary results. Remote Sens. Environ. 2002, 83, 149-162. [CrossRef]

58. Jin, Y.; Schaaf, C.B.; Woodcock, C.E.; Gao, F.; Li, X.; Strahler, A.H.; Lucht, W.; Liang, S. Consistency of MODIS surface bidirectional reflectance distribution function and albedo retrievals: 1. Validation. J. Geophys. Res. Atmos. 2003, 108, 145-158. [CrossRef]

59. Salomon, J.G.; Schaaf, C.B.; Strahler, A.H.; Gao, F.; Jin, Y. Validation of the MODIS Bidirectional Reflectance Distribution Function and albedo retrievals using combined observations from the Aqua and Terra platforms. IEEE Trans. Geosci. Remote Sens. 2006, 44, 1555-1564. [CrossRef]

60. Liu, J.; Schaaf, C.; Strahler, A.; Jiao, Z.; Shuai, Y.; Zhang, Q.; Roman, M.; Augustine, J.A.; Dutton, E.G. Validation of moderate resolution imaging spectroradiometer (MODIS) albedo retrieval algorithm: Dependence of albedo on solar zenith angle. J. Geophys. Res. Atmos. 2009, 114, D01106. [CrossRef]

61. Wang, Z.; Schaaf, C.B.; Strahler, A.H.; Chopping, M.J.; Román, M.O.; Shuai, Y.; Woodcock, C.E.; Hollinger, D.Y.; Fitzjarrald, D.R. Evaluation of MODIS albedo product (MCD43A) over grassland, agriculture and forest surface types during dormant and snow-covered periods. Remote Sens. Environ. 2014, 140, 60-77. [CrossRef]

62. Román, M.O.; Schaaf, C.B.; Woodcock, C.E.; Strahler, A.H.; Yang, X.; Braswell, R.H.; Curtis, P.S.; Davis, K.J.; Dragoni, D.; Goulden, M.L.; et al. The MODIS (Collection V005) BRDF/albedo product: Assessment of spatial representativeness over forested landscapes. Remote Sens. Environ. 2009, 113, 2476-2498. [CrossRef]

63. Shuai, Y.; Masek, J.G.; Gao, F.; Schaaf, C.B.; He, T. An approach for the long-term 30-m land surface snow-free albedo retrieval from historic Landsat surface reflectance and MODIS-based a priori anisotropy knowledge. Remote Sens. Environ. 2014, 152, 467-479. [CrossRef]

64. Vermote, E.; Justice, C.; Claverie, M.; Franch, B. Preliminary analysis of the performance of the Landsat 8/OLI land surface reflectance product. Remote Sens. Environ. 2016, 185, 46-56. [CrossRef]

65. Wang, Z.; Schaaf, C.; Lattanzio, A.; Carrer, D.; Grant, I.; Román, M.; Camacho, F.; Yu, Y.; Sánchez-Zapero, J.; Nickeson, J. Global Surface Albedo Product Validation Best Practices Protocol. Version 1.0. In Best Practice for Satellite Derived Land Product Validation: Land Product Validation Subgroup (WGCV/CEOS); Wang, Z., Nickeson, J., Román, M., Eds.; Land Product: Božice, Czech Republic, 2019. [CrossRef]

66. Stroeve, J.; Box, J.E.; Wang, Z.; Schaaf, C.; Barrett, A. Re-evaluation of MODIS MCD43 greenland albedo accuracy and trends. Remote Sens. Environ. 2013, 138, 199-214. [CrossRef]

67. Wang, Z.; Schaaf, C.B.; Sun, Q.; Shuai, Y.; Román, M.O. Capturing rapid land surface dynamics with Collection V006 MODIS BRDF/NBAR/Albedo (MCD43) products. Remote Sens. Environ. 2018, 207, 50-64. [CrossRef]

68. Elmes, A.; Levy, C.; Erb, A.; Hall, D.K.; Scambos, T.A.; Digirolamo, N.; Schaaf, C. Consequences of the 2019 greenland ice sheet melt episode on albedo. Remote Sens. 2021, 13, 227. [CrossRef]

69. Shuai, Y.; Schaaf, C.B.; Strahler, A.H.; Liu, J.; Jiao, Z. Quality assessment of BRDF/albedo retrievals in MODIS operational system. Geophys. Res. Lett. 2008, 35, 1-5. [CrossRef]

70. Schaepman-Strub, G.; Schaepman, M.E.; Painter, T.H.; Dangel, S.; Martonchik, J.V. Reflectance quantities in optical remote sensing-definitions and case studies. Remote Sens. Environ. 2006, 103, 27-42. [CrossRef] 
71. Roujean, J.L.; Leroy, M.; Dechamps, P. A bidirectional reflectance model of the Earth's surface for the correction of remote sensing data. J. Geophys. Res. Atmos. 1992, 97, 20455-20468. [CrossRef]

72. Wanner, W.; Li, X.; Strahler, A.H. On the derivation of kernels for kernel-driven models of bidirectional reflectance. J. Geophys. Res. Atmos. 1995, 100, 21077-21089. [CrossRef]

73. Li, X.; Gao, F.; Chen, L.; Strahler, A.H. Derivation and validation of a new kernel for kernel-driven BRDF models. Remote Sens. Earth Sci. Ocean. Sea Ice Appl. 1999, 3868, 368. [CrossRef]

74. Lewis, P.; Barnsley, M. Influence of the sky radiance distribution on various formulations of the earth surface albedo. Proc. Conf. Phys. Meas. Signat. Remote Sens. 1994, pp. 707-715. Available online: http://www2.geog.ucl.ac.uk/ \{\}plewis/LewisBarnsley1994. pdf (accessed on 13 October 2021).

75. Román, M.O.; Schaaf, C.B.; Lewis, P.; Gao, F.; Anderson, G.P.; Privette, J.L.; Strahler, A.H.; Woodcock, C.E.; Barnsley, M. Assessing the coupling between surface albedo derived from MODIS and the fraction of diffuse skylight over spatially-characterized landscapes. Remote Sens. Environ. 2010, 114, 738-760. [CrossRef]

76. Deering, D.W.; Eck, T.F.; Grier, T. Shinnery Oak Bidirectional Reflectance Properties and Canopy Model Inversion. IEEE Trans. Geosci. Remote Sens. 1992, 30, 339-348. [CrossRef]

77. Deering, D.W.; Eck, T.F.; Banerjee, B. Characterization of the reflectance anisotropy of three Boreal forest canopies in springsummer. Remote Sens. Environ. 1999, 67, 205-229. [CrossRef]

78. He, T.; Liang, S.; Wang, D.; Cao, Y.; Gao, F.; Yu, Y.; Feng, M. Evaluating land surface albedo estimation from Landsat MSS, TM, $\mathrm{ETM}+$, and OLI data based on the unified direct estimation approach. Remote Sens. Environ. 2018, 204, 181-196. [CrossRef]

79. Jiao, Z.; Hill, M.J.; Schaaf, C.B.; Zhang, H.; Wang, Z.; Li, X. An anisotropic flat index (AFX) to derive BRDF archetypes from MODIS. Remote Sens. Environ. 2014, 141, 168-187. [CrossRef]

80. Zhang, H.; Jiao, Z.; Dong, Y.; Li, X. Evaluation of BRDF archetypes from MODIS multi-angular observations. IEEE Geosci. Remote Sens. Symposium. 2014, 4738-4741. [CrossRef]

81. Zhang, H.; Jiao, Z.; Dong, Y.; Li, X. Evaluation of BRDF archetypes for representing surface reflectance anisotropy using MODIS BRDF data. Remote Sens. 2015, 7, 7826-7845. [CrossRef]

82. Liang, S.; Shuey, C.J.; Russ, A.L.; Fang, H.; Chen, M.; Walthall, C.L.; Daughtry, C.S.T.; Hunt, R. Narrowband to broadband conversions of land surface albedo: II. Validation. Remote Sens. Environ. 2003, 84, 25-41. [CrossRef]

83. Gao, B.; Jia, L.; Wang, T. Derivation of land surface albedo at high resolution by combining HJ-1A/B reflectance observations with MODIS BRDF products. Remote Sens. 2014, 6, 8966-8985. [CrossRef]

84. Cescatti, A.; Marcolla, B.; Santhana Vannan, S.K.; Pan, J.Y.; Román, M.O.; Yang, X.; Ciais, P.; Cook, R.B.; Law, B.E.; Matteucci, G.; et al. Intercomparison of MODIS albedo retrievals and in situ measurements across the global FLUXNET network. Remote Sens. Environ. 2012, 121, 323-334. [CrossRef]

85. Hao, D.; Wen, J.; Xiao, Q.; You, D.; Tang, Y. An Improved Topography-Coupled Kernel-Driven Model for Land Surface Anisotropic Reflectance. IEEE Trans. Geosci. Remote Sens. 2020, 58, 2833-2847. [CrossRef] 